\title{
Structured decision-making for sustainable water infrastructure planning and four future scenarios
}

\author{
Judit Lienert • Lisa Scholten • Christoph Egger • \\ Max Maurer
}

Received: 11 January 2013/ Accepted: 11 June 2014/Published online: 4 July 2014

(C) Springer-Verlag Berlin Heidelberg and EURO - The Association of European Operational Research Societies 2014

\begin{abstract}
Water supply and wastewater infrastructures are vital for human wellbeing and environmental protection; they adhere to the highest standards, are expensive and long-lived. Because they are also aging, substantial planning is required. Climate and socio-economic change create large planning uncertainties and simple projections of past developments are no longer adequate. This paper presents the initial phases of a structured decision-making (SDM) procedure which is designed to increase the sustainability of water infrastructure planning and includes various stakeholders in an exemplary Swiss case study. We evaluate the SDM approach critically based on stakeholder feedback, give general recommendations and provide ample material to make it applicable to other settings. We carried out 27 interviews and two stakeholder workshops. We identified important objectives for water infrastructure planning, including all three sustainability pillars and their respective attributes (indicators, benchmarks) to measure how well the objectives are achieved. We then created strategic decision alternatives, including "business-as-usual" upgrades of the central water supply and wastewater system as well as semi- to fully decentralized alternatives. To tackle future uncertainty, we developed four socio-demographic scenarios. We used these to test the robustness of decision alternatives in a later Multi-Attribute Utility Theory analysis. Additionally,
\end{abstract}

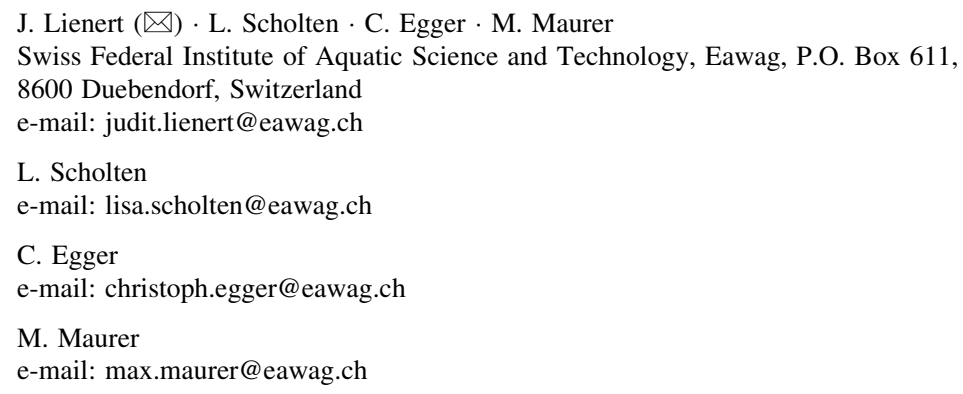


we contribute to the topical discussion of combining scenario planning with multicriteria decision analysis and demonstrate how various scenarios can stimulate creativity when generating decision alternatives. Their internal consistency is ensured by rigorously specifying them using a strategy generation table. Our SDM procedure can be adapted to inform decisions about sustainable water infrastructures in other contexts.

Keywords Decision-making - Scenario planning - Stakeholder participation Structuring · Water infrastructure · Water management

Mathematics subject classification $\quad 90 \mathrm{~B} 50$

\section{Introduction}

\subsection{Structured decision-making}

Decision-making for environmental management is complex. It typically affects various actors and requires difficult trade-offs across many environmental and socio-economic objectives. If future generations are affected, long time spans need to be considered. Multi-criteria decision analysis (MCDA) provides a useful framework for making better-informed, more sustainable and participatory decisions (e.g., Belton and Stewart 2003; Clemen and Reilly 2001; Eisenführ et al. 2010; Keeney 1992; Keeney and Raiffa 1976). There are numerous examples of environmental applications (reviewed in Huang et al. 2011; Linkov and Moberg 2012).

To support the choice between decision alternatives, mathematical models can be applied that integrate the decision makers' (subjective) preferences for outcomes with the (objective) performance of the various alternatives with respect to a set of previously determined objectives. However, as nicely outlined in a book by Gregory et al. (2012a), it often suffices to structure the decision together with the stakeholders to clarify the trade-offs and find an agreement between the parties. This structuring process may then-but need not-be followed by a formal MCDA, whereby modeling and expert knowledge used to predict outcomes are combined with stakeholder preferences.

In this paper, we focus on the first three steps of structured decision-making (SDM; Gregory et al. 2012a) that are crucial in any decision, but are often neglected (e.g., Belton and Stewart 2003). The following steps are usually carried out (see textbooks, e.g., Belton and Stewart 2003; Clemen and Reilly 2001; Eisenführ et al. 2010; Gregory et al. 2012a; Keeney 1992; Keeney and Raiffa 1976): (1) clarify the decision context; (2) define objectives and attributes; (3) develop alternatives; (4) estimate consequences; (5) evaluate trade-offs and select alternatives (this is a combination of the decision makers' subjective preferences with the objective consequences of the alternatives); and (6) implement, monitor and review. Many applications of MCDA focus on estimating the consequences of decision 
alternatives (step 4) and evaluating the trade-offs to select best alternatives (step 5), while the initial structuring steps (1-3) are treated rather superficially. However, setting up the decision problem in a sound way is absolutely crucial and may have a much larger effect on the result (in step 5) than the quantitative steps (4 and 5). In an early survey, Tilanus et al. (1983) found that the most frequent reason for the failure of operational research interventions is the mismatch between the problem and the model used (cited in Belton and Stewart 2003; also see Gregory et al. 2012a). For example, if decision makers receive good support, a much larger number of fundamental objectives are generated (step 2) than if they have to rely on own ideas (e.g., Bond et al. 2008, 2010). The decision alternatives (step 3) are often assumed to "just be there", without considering innovative solutions. This is a consequence of the frequently encountered bias of anchoring on the status quo and adhering to narrow conventions (e.g., Daily et al. 2000; Nutt 2004). Gregory et al. (2012a) argue that good decision-making does not always require quantitative modeling, but that structuring the decision in compliance with sound theory helps to discipline thinking and make decisions more transparent. In this paper, we, therefore, focus on the initial problem structuring steps one to three, exemplified with a case study application.

A linear additive value model is often used to calculate an overall value for each alternative (step 5) based on a weighted sum of the alternatives' consequences for each attribute (following multi-attribute value or utility theory, e.g., Belton and Stewart 2003; Eisenführ et al. 2010; Gregory et al. 2012a; Keeney and Raiffa 1976). All models require attributes (indicators) that make the objectives measurable, a prediction to quantify how well each alternative fulfills the objectives, and preference information from decision makers. Each attribute then receives an importance weighting and a value function transforms attribute levels to a neutral scale between 0 and 1 . Alternatives that achieve the highest values ${ }^{1}$ are proposed and discussed with the decision makers.

\subsection{Combining scenario planning with MCDA}

Water infrastructures are long-lived, with average pipe lifespans of water supply and sewerage of some 80 years (Martin 2009). It is thus especially important to consider intergenerational equity, which is a core aspect of sustainable development ${ }^{2}$ (WCED 1987; for a conceptual discussion see Wuelser et al. 2012). For such time ranges, the future is "deeply uncertain" 3 and it is impossible to use probabilistic

\footnotetext{
${ }^{1}$ Formally, the linear additive value model is: $v(a)=\sum_{i=1}^{m} w_{i} v_{i}\left(a_{i}\right)$ where: $v(a)=$ total value of alternative $a, a_{i}=$ attribute level of alternative $a$ for attribute $i, v_{i}\left(a_{i}\right)=$ value for attribute $i$ of alternative $a, w_{i}=$ weights (or scaling constants) of attribute $i$, and sum of $w_{i}$ equals 1 .

2 "Sustainable development is development that meets the needs of the present without compromising the ability of future generations to meet their own needs" (WCED 1987, p. 43).

3 "Level 3 uncertainty represents deep uncertainty about the mechanisms and functional relationships being studied. We know neither the functional relationships nor the statistical properties, and there is little scientific basis for placing believable probabilities on scenarios. In the case of uncertainty about the future, Level 3 uncertainty is often captured in the form of a wide range of plausible scenarios. Level 4 uncertainty implies the deepest level of recognized uncertainty; in this case, we only know that we do not know" (Walker et al. 2010, p. 918).
} 
models (e.g., Walker et al. 2010). However, most MCDA methods are deterministic and the uncertainties are often internal (epistemic uncertainty or imprecision; reviewed in Stewart et al. 2013; also see Reichert et al. 2014). ${ }^{4}$

Scenario building is a tool used to systematically explore the future without trying to predict it (e.g., Ringland 2002; Schnaars 1987; Schoemaker 1995). Early examples come from business strategy formation (e.g., the famous Shell example: Wack 1985). There are also numerous environmental applications (e.g., Peterson et al. 2003; Swart et al. 2004), including strategic planning for urban water infrastructures (Dominguez et al. 2011; Lienert et al. 2006; Störmer et al. 2009; Truffer et al. 2010; review in: Dong et al. 2013).

Recently, researchers started combining scenario planning with MCDA. This combination is not trivial, because it adds an additional dimension to the already highly complex MCDA analyses. One problem is how to include stakeholder preferences. If it is assumed that these preferences differ for different scenarios, a value function for each decision-maker must be constructed for each scenario (e.g., Karvetski et al. 2009, 2011; Lambert et al. 2012; Montibeller et al. 2006; Stewart et al. 2013), so that the elicitation process becomes more laborious (Ram and Montibeller 2013; Ram et al. 2011). Practicable shortcuts would be eliciting shifts in the relative importance of certain value function components compared to a baseline value function (e.g., Karvetski et al. 2009, 2011; Lambert et al. 2012). Stewart et al. (2013) propose aggregating across scenarios by introducing "metacriteria", but this approach remains to be tested in practice.

\subsection{Water infrastructure planning}

Water supply and wastewater disposal infrastructures are crucial for the provision of clean water and water for firefighting, urban hygiene, protection against flooding and water pollution control. In many OECD countries, the infrastructures meet the highest standards and are expensive; the replacement values of the public wastewater system (excluding household connections) are typically between US\$ 2,600 and 4,800 per person (Maurer et al. 2005). The annual investment need in OECD countries in the water sector is approximately $0.75 \%$ of GDP (Cashman and Ashley 2008), which translates into US\$ 300,000 million annually (OECD 2012). Despite their success in the industrialized world, centralized infrastructure systems are increasingly criticized for their lack of sustainability (e.g., using clean water to flush toilets, loss of nutrients, e.g., phosphate that could be recycled). A central system with extensive underground pipe networks and large treatment plants is also very inflexible. Decentralized options for water supply and wastewater disposal are

\footnotetext{
${ }^{4}$ Stewart et al. (2013, pp. 683-684) distinguish "internal uncertainty" from "external driving forces". Internal uncertainties concern e.g. the imprecision of measurements; probability frameworks can deal with these. Stewart et al. (2013) also classify epistemic uncertainty as internal uncertainty. In epistemic interpretations, probabilities can be used to quantify human (expert) knowledge or belief concerning the probability of something occurring. How to conceptually deal with uncertainties in environmental management with a specific focus on MCDA is discussed by Reichert et al. (2014). In contrast, external uncertainties may much more strongly affect the outcome of decisions we make today. These uncertainties (e.g. future climate, demographic or economic development) can often be better captured by the scenario approach.
} 
gaining increasing momentum in the engineering community (e.g., Guest et al. 2009; Larsen et al. 2009, 2012; Libralato et al. 2012).

Despite long service lives, infrastructures are often planned with mid-term projections ( $<25$ years) from past developments. This approach is deficient by not accounting for future developments. Due to climate change, we can expect severe droughts and more frequent heavy storms in Central Europe (e.g., Kysely et al. 2011). Thus, sewers may have increasing difficulty in reliably draining storm water, resulting in more combined sewer overflows polluting rivers and lakes, and in more urban floods (e.g., Arnbjerg-Nielsen and Fleischer 2009; Butler et al. 2007; Patz et al. 2008). Socio-demographic and economic pressures add to planning uncertainty_ "the challenge is daunting" (Milly et al. 2008).

We know only few applications of MCDA in urban water infrastructure planning for OECD countries. Most MCDA projects in the water sector concern water policy and water resource management (e.g., Hämäläinen et al. 2001; Reichert et al. 2007). The same applies to infrastructures, for which water resource management, including hydroelectric power schemes, is often considered (e.g., Eder et al. 1997; Kodikara et al. 2010), but rarely urban drinking and wastewater management (see review by Hajkowicz and Collins 2007 and an early example by Keeney et al. 1996). From the water engineering sector, there is growing interest in comparing different infrastructure options using "indicators", usually with life cycle analysis (LCA) (Balkema et al. 2001; Lundie et al. 2004; Palme et al. 2005). The indicators cover environmental and social criteria such as "acceptance" (of phosphorus products from sewage), "reliability of service" and "working conditions" (Palme et al. 2005). In one case, non-conventional decentralized options were evaluated, but they were based on purely environmental indicators (Lundie et al. 2004). However, sustainability indicators remain an "elusive concept" (Ashley et al. 2008). To our knowledge, the development of a comprehensive objectives hierarchy based on multi-attribute value theory (MAVT; e.g., Belton and Stewart 2003; Eisenführ et al. 2010; Keeney 1992; Keeney and Raiffa 1976) for use in a full MCDA analysis and accounting for long-term changes is new in the field.

Many municipalities in Switzerland are facing the challenges described above. They need to rehabilitate and plan their long-lived water infrastructures so that they meet today's as well as tomorrow's societal and sustainability demands. To mirror research with real stakeholders, we identified a suitable case study that allowed us to structure the project including different types of stakeholders and different methods for participation. We identified the "Mönchaltorfer Aa" region near Zurich as suitable (and willing to participate). It comprises four smaller communities with about 24,200 inhabitants, extensive agriculture as well as urban development pressure from Zurich. The nearby Lake Greifensee is an important recreational and nature protection area. It is one of the few Swiss lakes still affected by eutrophication stemming from wastewater discharges and agriculture (AWEL 2003, 2006). In summer, there is a danger of fish kills due to oxygen depletion in deeper water layers and high temperatures in surface layers (AWEL 2003). The discharge from wastewater treatment plants (WWTPs) into smaller rivers upstream of Lake Greifensee results in inadequate river water quality, including elevated concentrations of micropollutants (AWEL 2006). The project presented here 
focused on developing instruments for decision support rather than on elaborating specific recommendations for action. We aimed to provide a procedural tool for "Sustainable Water Infrastructure Planning" (SWIP 2013) that enhances planning efficiency, can cope with uncertainty and is well accepted.

\subsection{Objectives of this paper}

The aim is to present and critically discuss the initial SDM structuring and decisionmaking steps one to three based on Gregory et al. (2012a) and on stakeholder feedback. This discussion aims to find out good practices and to give guidance on how to carry out an SDM process in a real case. As an illustration, we use a complex real example of water infrastructure planning in Switzerland. We include a broad range of stakeholders and develop a comprehensive set of decision objectives, diverse alternatives and four future scenarios. Although it was developed in a local stakeholder process, we set up our SDM framework so that it can be adapted to water infrastructure decisions in other countries.

\section{SDM process and application in the Swiss case}

Below, we describe each initial problem structuring step (1-3) of the SDM process from a general point of view and then illustrate how we applied this to the Swiss case study. We thus guide through clarifying the decision context and selecting stakeholders (step 1), defining the objectives and attributes with interviews and workshops (step 2), and generating decision alternatives (step 3). As an additional step, we present the development of future scenarios.

\subsection{Step (1): clarify the decision context}

\subsubsection{General procedure to clarify the decision context}

In the first step of the SDM process, the decision context, scope and boundaries of the decision problem are clarified. A good framework to guide environmental management choices includes not only scientific and practical insights about ecological aspects, monetary values, but also the values and judgments of different stakeholders. The SDM approach seeks to disentangle these aspects and raises the following questions (Gregory et al. 2012a, p. 8): “(1) What is the decision (or series of decisions) to be made, by whom and when? (2) What is the range of alternatives and objectives that can be considered (without details at this stage)? (3) What kind of decision is it and how could it usefully be structured? What kinds of analytical tools will be needed? What level and kind of consultation is appropriate?"

A useful approach here may be "decision sketching", as illustrated with examples from environmental management by Gregory et al. (2012a). Means-ends networks, preliminary objectives hierarchies, consequence tables, influence diagrams or decision trees are suggested for structuring (also see Clemen and Reilly 2001; Eisenführ et al. 2010). 
This step also involves deciding who should participate. The SDM process is designed for groups of five to twenty-five people who work intensively on a complex problem (Gregory et al. 2012a). A decision sketch can also help to identify stakeholders. After clarifying which environmental and societal endpoints are affected by the decision alternatives, one can ask: "Who will care about these outcomes?" However, Gregory et al. (2012a) provide little guidance on ways of choosing these participants.

\subsubsection{Procedure applied in the SWIP application example}

The aim of our project was to find a case that is suitable to tackle the research questions, rather than solving a one-off environmental decision problem. The study region "Mönchaltorfer Aa" well addressed many required aspects (several communities involved, water quality problems, data availability) and allowed us to collaborate with other scientific projects. Here, we drew the boundaries based on the willingness of communities to participate in our research project. In our application, we placed much more emphasis on selecting stakeholders than is usually reported in the SDM literature. To identify those who play a role in water infrastructure planning or who could be affected by it, we carried out a stakeholder and social network analysis (Lienert et al. 2013). We found that over 40 actors were involved, with a clear dominance of local and engineering actors. The network analysis confirmed the hypothesis of a strongly fragmented water sector, namely between water supply and wastewater (and others), and between decision-making levels. ${ }^{5}$ We used this work to select the workshop participants and interview partners in the paper presented here. Besides obvious stakeholders such as the local planning engineers and municipalities, representatives who were perceived to be less important were also included, such as the cantonal and national authorities (for details see Lienert et al. 2013).

\subsection{Step (2): define objectives and attributes}

\subsubsection{General procedure to create the objectives hierarchy}

Objectives define "what matters" in the decision, and attributes (performance measures/indicators) make them operational (Gregory et al. 2012a). Objectives can be organized hierarchically and provide a framework for transparently comparing the performance of alternatives. It is crucial that the decision makers (in our example the selected local, cantonal and national stakeholders) understand and accept the objectives and attributes and also that specific rules are followed: the objectives should comprehensively cover the decision, be fundamental, concise and sensitive, i.e. they should help to distinguish between alternatives (e.g., if costs are the same in all alternatives, "low costs" are not suitably sensitive). They should be

\footnotetext{
5 These include local practitioners (engineers or operating staff of treatment plants), representatives from administration and politics from the municipalities, the region (e.g. cantonal agency for waste, water, energy and air) and at national level (e.g. environmental protection agency; associations of water professionals).
} 
understandable, simple, non-ambiguous, non-redundant and preferentially independent (for the additive model; e.g., Belton and Stewart 2003; Eisenführ et al. 2010; Gregory et al. 2012a; Keeney and Raiffa 1976).

Although people usually have a good idea about what is important to them, it is not trivial to generate good objectives for environmental decisions. Creativity techniques, such as brainstorming a wish list, or considering shortcomings or new perspectives, can help (Clemen and Reilly 2001). Based on environmental case study examples, Gregory et al. (2012a) recommend five steps (also see Keeney 1992; Keeney and Raiffa 1976): (1) brainstorm, (2) separate means from ends, (3) separate "process" or "strategic" from "fundamental" objectives, (4) build hierarchy and (5) test the usefulness of the objectives. It is crucial to avoid "means" objectives, which are important only to achieve a more fundamental objective. Means-ends networks can be used here (nicely illustrated in Clemen and Reilly 2001 and Gregory et al. 2012a). If much is known, a top-down creation of the objectives hierarchy is recommended; it helps to ask: "What do you mean by that?" for a more detailed description of an objective (Clemen and Reilly 2001). If little is known, users are advised to move from lower to higher levels of the hierarchy.

To quantify objectives, attributes are needed (Belton and Stewart 2003; Eisenführ et al. 2010; Gregory et al. 2012a). "Natural" attributes (e.g., \$, hours) are clearly preferable to "proxy" ones, which operationalize objectives only indirectly. However, the latter often cannot be avoided in environmental management (e.g., using "area" to measure "species abundance"). Constructed attributes such as seven-point Likert scales (Likert 1932), known from psychological questionnaires, may also be useful for environmental decisions (Gregory et al. 2012a). However, expert judgments are rarely unambiguous. It is thus recommended to combine numerical scales with narrative descriptions ("defined impact scales").

\subsubsection{Procedure applied in the SWIP application example}

In our application, the objectives' hierarchy was generated in a multi-step, iterative procedure. This comprised a desktop analysis to create a preliminary objectives hierarchy (top-down approach), face-to-face interviews with stakeholders and a stakeholder workshop. Our aim was to generate a generic hierarchy also applicable to other cases of water infrastructure planning.

The preliminary objectives' hierarchy set up by the project team was based on engineering requirements. "Good water supply" includes the uninterrupted provision of drinking water in high quality and quantity and water for firefighting. Objectives of the wastewater system include "urban hygiene" and the "protection of water bodies" as stipulated in environmental laws. We included "low costs" and "intergenerational equity" to cover all pillars of sustainability. More details are given in Lienert et al. (2014).

2.2.2.1 Face-to-face interviews We discussed these objectives in the 27 face-toface interviews for the stakeholder and network analysis (Lienert et al. 2013). We then described the purpose of the objectives (to help choose between ten infrastructure decision alternatives) and their properties (see above). First, the 
interviewees freely stated which objectives they found appropriate, and only then did we show our own highest-level objectives. We assigned their objectives to ours and asked whether they agreed or if a new top-level objective was required. In this way, we worked through all branches of the hierarchy. To select objectives, we asked for an importance classification. ${ }^{6} \mathrm{We}$ also asked for ideas about attributes and for general feedback. ${ }^{7}$ We categorized the answers and calculated the number of comments in each category.

Five of the six fundamental objectives at the highest hierarchical level were perceived as essential or important by nearly everyone involved (see Lienert et al. 2014). Some additional objectives were proposed. Most were already covered under a different title or were means objectives. For example, "good state of infrastructure" is a means objective to achieve, e.g., "safe water supply and wastewater disposal". Several suggestions included trade-offs that will be calculated in the MCDA (e.g., "optimized cost-benefits"). We also considered "transparency" to be covered by the SDM procedure. We decided that "protection of floodplains" is outside our systems boundary, but included the new objective "high quality of management and operations" in the revised hierarchy. We later discussed the objectives vigorously in the project team and developed a larger hierarchy.

2.2.2.2 Stakeholder workshops In our application example, we carried out two stakeholder workshops in the study region in April and May 2011 ( $5 \mathrm{~h}$ each). The first was a scenario workshop (see below); in the second, we created alternatives (see below) and discussed the objectives. This second workshop had 20 participants, identified by the stakeholder analysis, including representatives from different municipalities, sectors, institutions and companies at local, cantonal and national level. We presented the objectives hierarchy and the requirements for "good" objectives. These were familiar to most participants, thanks to the previous interview. They systematically worked through the hierarchy and discussed in pairs which objectives they found really fundamental or which were missing. We collected their notes and discussed the objectives in the plenum. Each participant was asked to assign points to the three objectives perceived as the least relevant. At the end of the workshop, we asked for feedback.

No objectives could be deleted based on the workshop discussions (see Lienert et al. 2014); we had hoped that we could reduce the large hierarchy to a smaller, more manageable set. Objectives describing the classic infrastructure system ("safe drinking water supply", "safe wastewater disposal") were almost undisputed. Most of the discussion focused on objectives characterizing decentralized water supply and wastewater treatment alternatives. For water supply, these were "household

\footnotetext{
${ }^{6}$ Essential objectives (without this objective I cannot judge whether a fundamental objective has been reached), important (without this it is difficult...) and nice to have (attainment of the fundamental objective can be judged without this).

7 Specific questions: "What would be next step and who should do it?"/"What are your expectations, fears or hopes w.r.t. our project and Eawag?" (Eawag is our research institute, i.e. the Swiss Federal Institute of Aquatic Science and Technology)/“Do you have general feedback, also concerning the interview or recommendations?".
} 
water of good quality" (lower quality than drinking water for washing, etc.; Fig. 1) and "water for firefighting", which in Switzerland is combined with the drinking water supply. For "low costs", the total annual costs were seen as most important, unlike "low cost fluctuations" and "easy fundraising", which we deleted later. The objectives of "high social acceptance" and "intergenerational equity" were most strongly questioned. Nevertheless, we kept most of the questioned objectives because neither the plenary discussion nor the distribution of points provided a clear justification to do so otherwise (Lienert et al. 2014). We also found it important to include all pillars of sustainable development (Wuelser et al. 2012), and we kept some objectives that were necessary to distinguish between alternatives (e.g., "flexible system adaptation" and "low time demand for end users").

\subsubsection{Final objectives hierarchy and attributes After the workshop, the project} team again revised the objectives and attributes. We decided for which attributes we could generate the predictions for each alternative ourselves (results of dimensioning and engineering models in SWIP, know-how, literature) and which required other expert information. For these, we asked one to four experts to define an adequate attribute, the worst- and best-possible values and the attribute levels of our decision alternatives (Table 1). If their judgments differed strongly, we increased the ranges, namely for "high co-determination of citizens" (two experts with different estimates). For "flexible system adaptation", judged by four engineers, we calculated the average and standard deviations. Alternatives with more than $10 \%$ deviation were discussed and the point of view defended (similar to a group Delphi; Schulz and Renn 2009). A final score was then assigned by the group, with larger interval ranges to depict higher uncertainty or variance.

The fundamental objectives of the final hierarchy are given in Fig. 1 and the attributes in Table 1 (for details including ranges, narrative descriptions and status quo, see Lienert et al. 2014). The objectives' hierarchy and attributes were constructed to analyze the case study, but also to be applicable to other cases; i.e., we consider them to be as exhaustive as practically possible. To make the work on our SWIP project manageable, we split the water supply and wastewater system (three PhD students and one postdoc work on the project), but collaborated closely to come up with a holistic hierarchy.

\subsection{Future scenarios}

Creating future scenarios are not part of standard SDM procedures. We introduced this step because a main aim of our project is to develop a decision procedure that can cope with uncertainty. We adapted four Swiss development scenarios from an earlier National Research Program (NRP 54; www.nfp54.ch) to our local case in the first stakeholder workshop in April 2011, following Truffer et al. (2010). We invited 22 members of the four communities, but not from the national and cantonal level, because we felt that local people should adapt the scenarios to their specific case. The exclusion of senior administrators also helped to create a comfortable workshop feeling. The 15 participants came from all four communities; they represented both water sectors and different roles (i.e. with a political or technical-engineering 


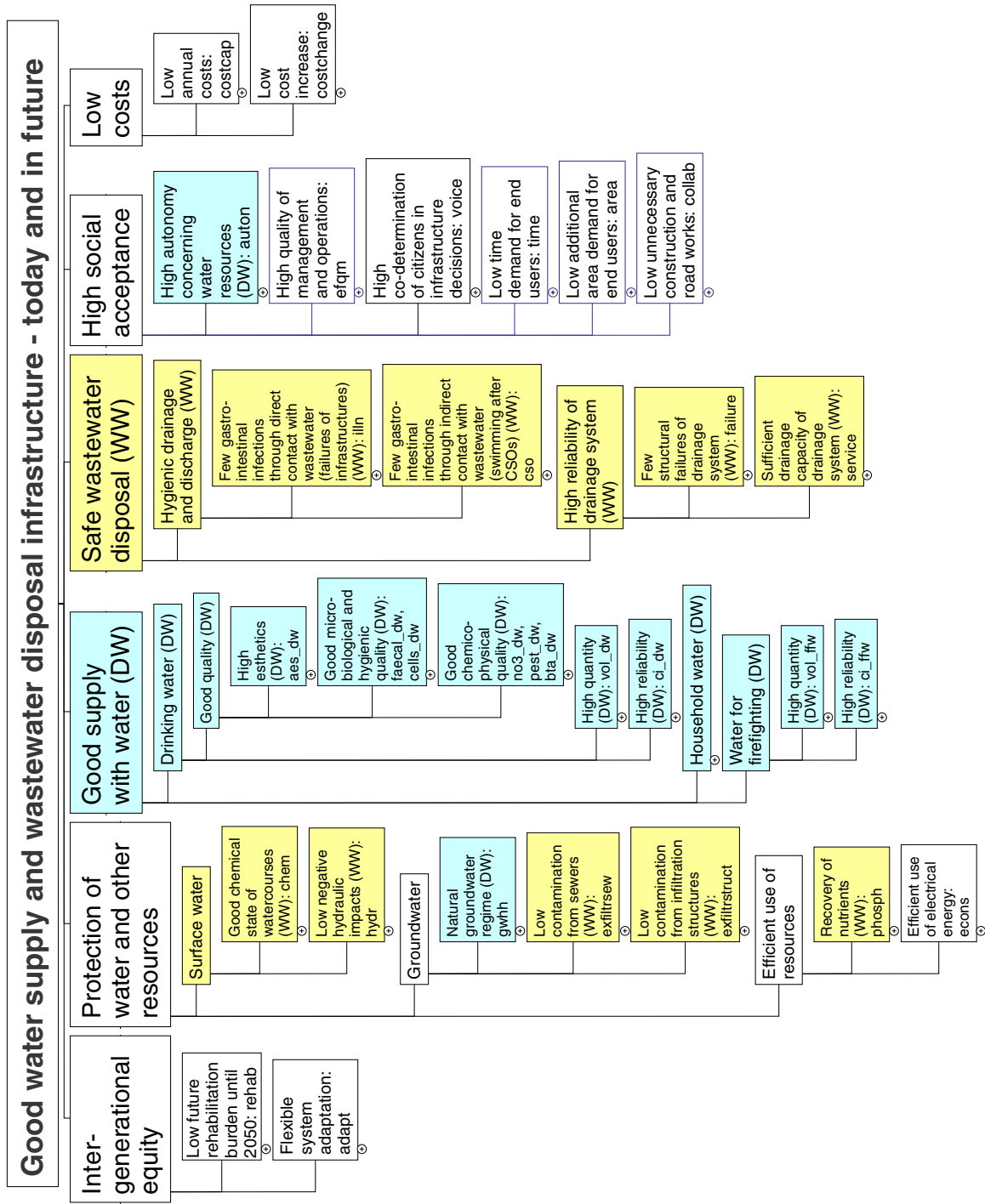

Fig. 1 Final objectives hierarchy as used in the SWIP project for water infrastructure decisions in the case study area of Mönchaltorfer Aa. The objectives hierarchy is transferable to other cases. Objectives without shading are used for the entire network, objectives with blue shading only apply to the water supply infrastructures ( $D W$ drinking water), and objectives with yellow shading only to the wastewater infrastructures ( $W W$ wastewater). After the colon, the short name(s) of the respective attributes are given. CSOs combined sewer overflows (discharge of mixed rain and wastewater to water bodies with only basic or no treatment)

focus). First, we presented the SWIP study and scenario planning: to create a picture of the future that is internally consistent and plausible, but not necessarily desirable or probable, the scenario descriptions are based on key factors that may differ in each future world (e.g., Schnaars 1987). The scenarios were depicted to the year 


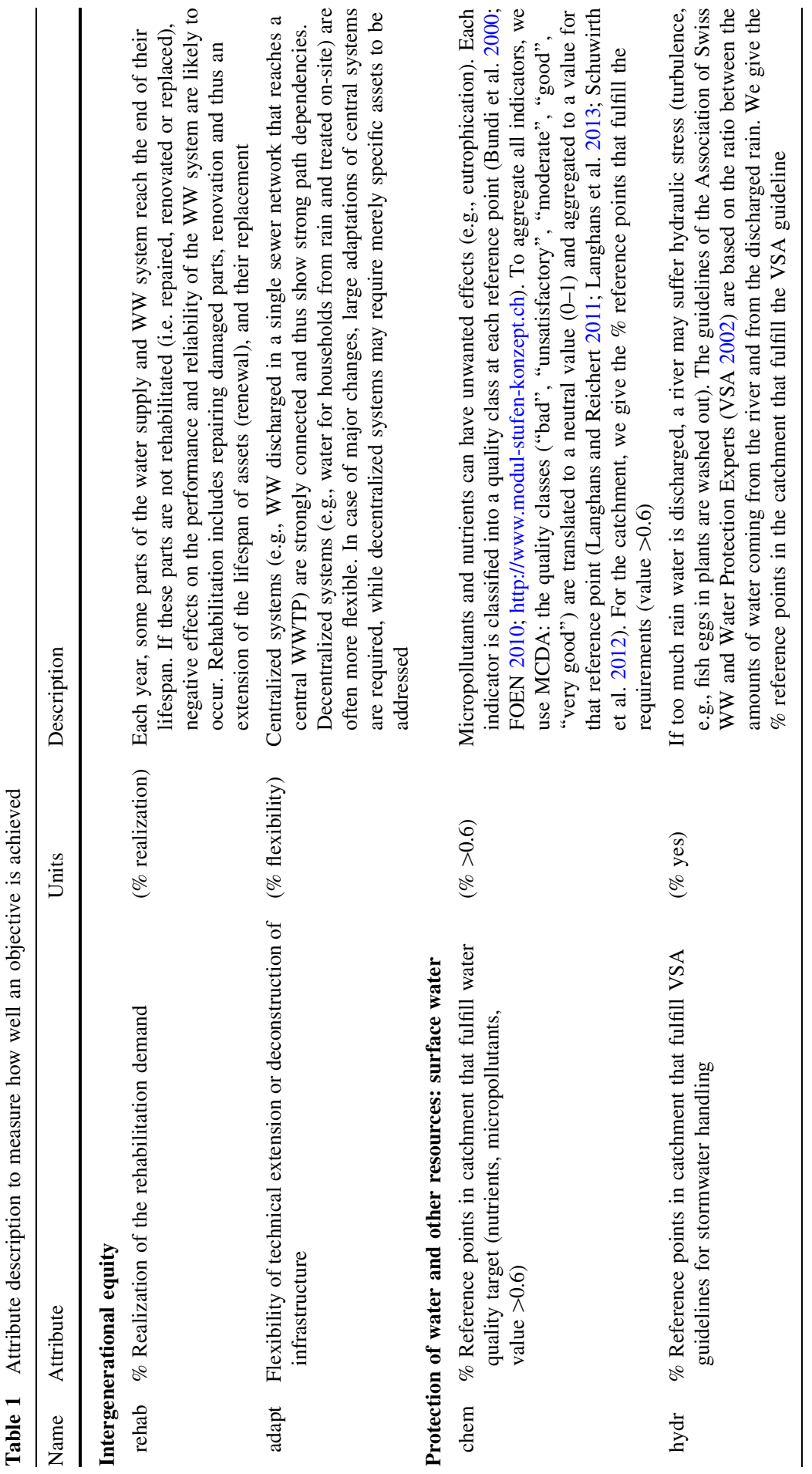




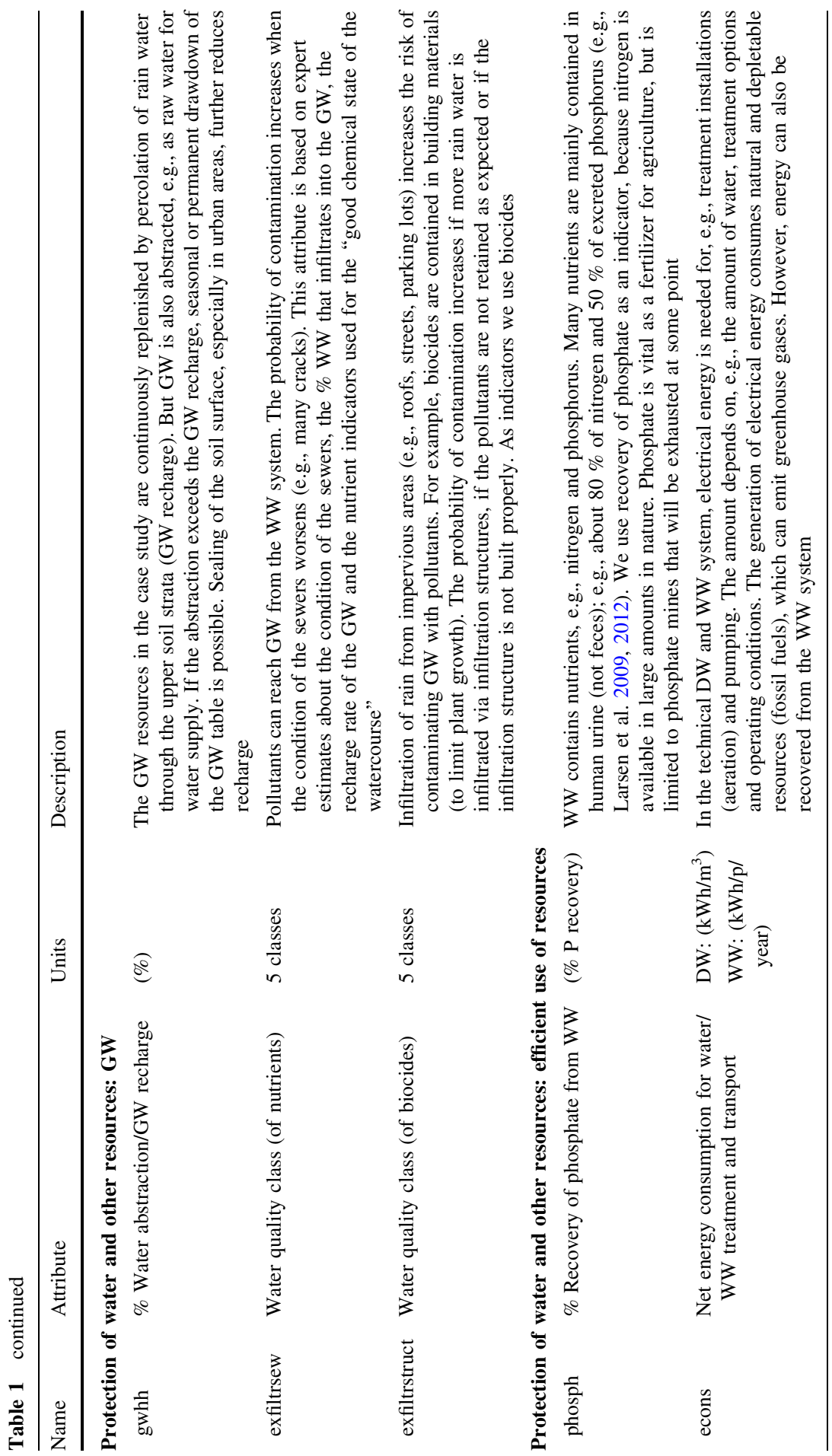




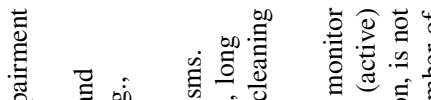

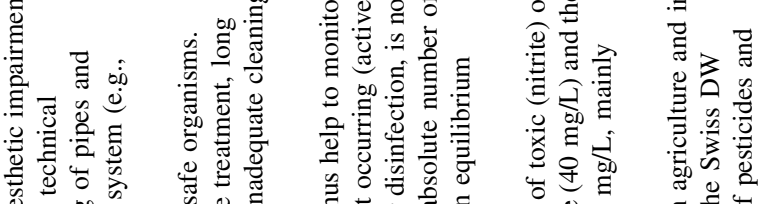

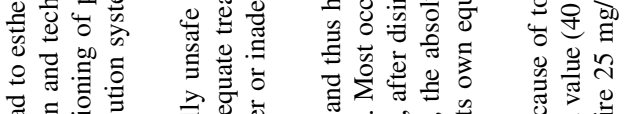

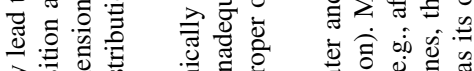

缃

늘

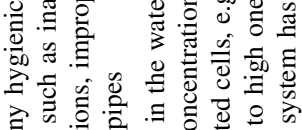

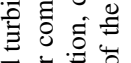

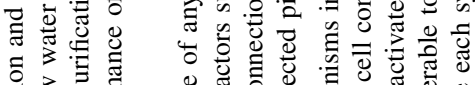

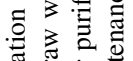

\&

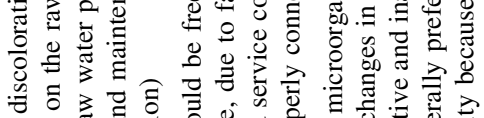

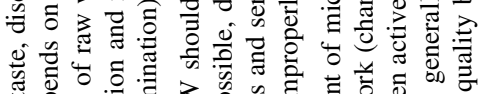

蛋

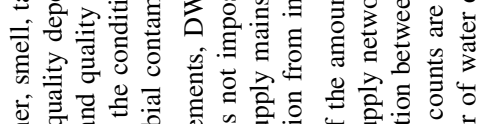

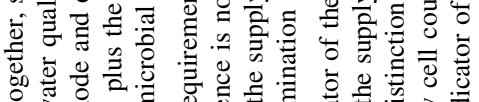

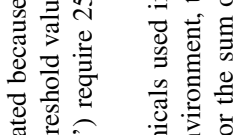

奇总

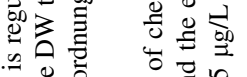

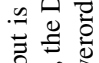

จ

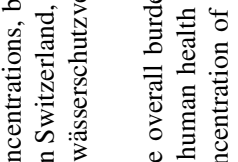

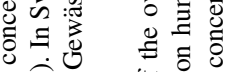

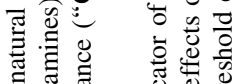

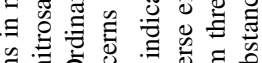

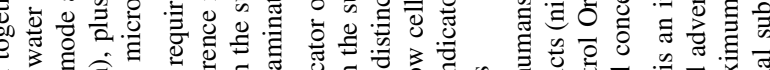

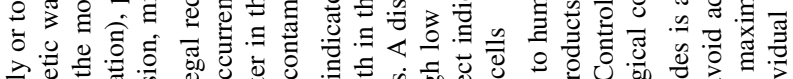

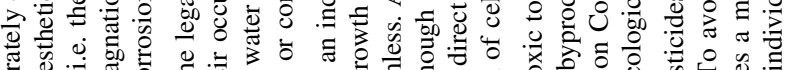

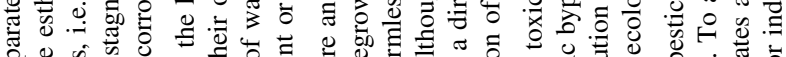

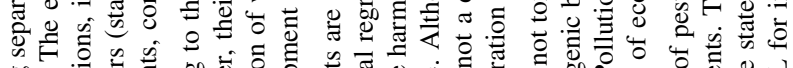

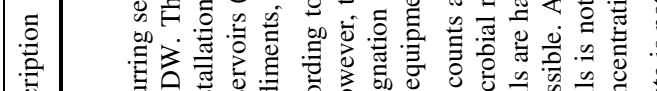

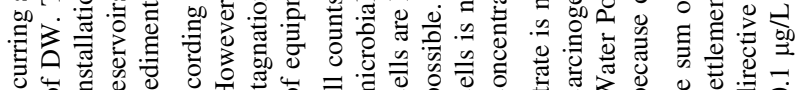
ठ

离

廌

क्ष

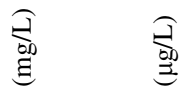

离

苞

范式

एक

氖晜

$\geqslant \geqslant$

壳

อีำ

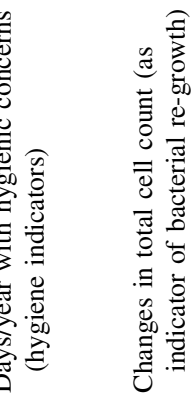

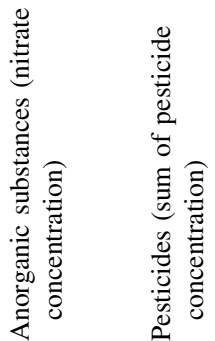

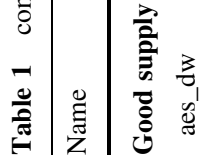

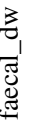

$\frac{3}{8}$
$\frac{1}{8}$

$\begin{array}{ll}3 & 3 \\ 0 & 0 \\ 0 & 0 \\ 0 & 0\end{array}$ 


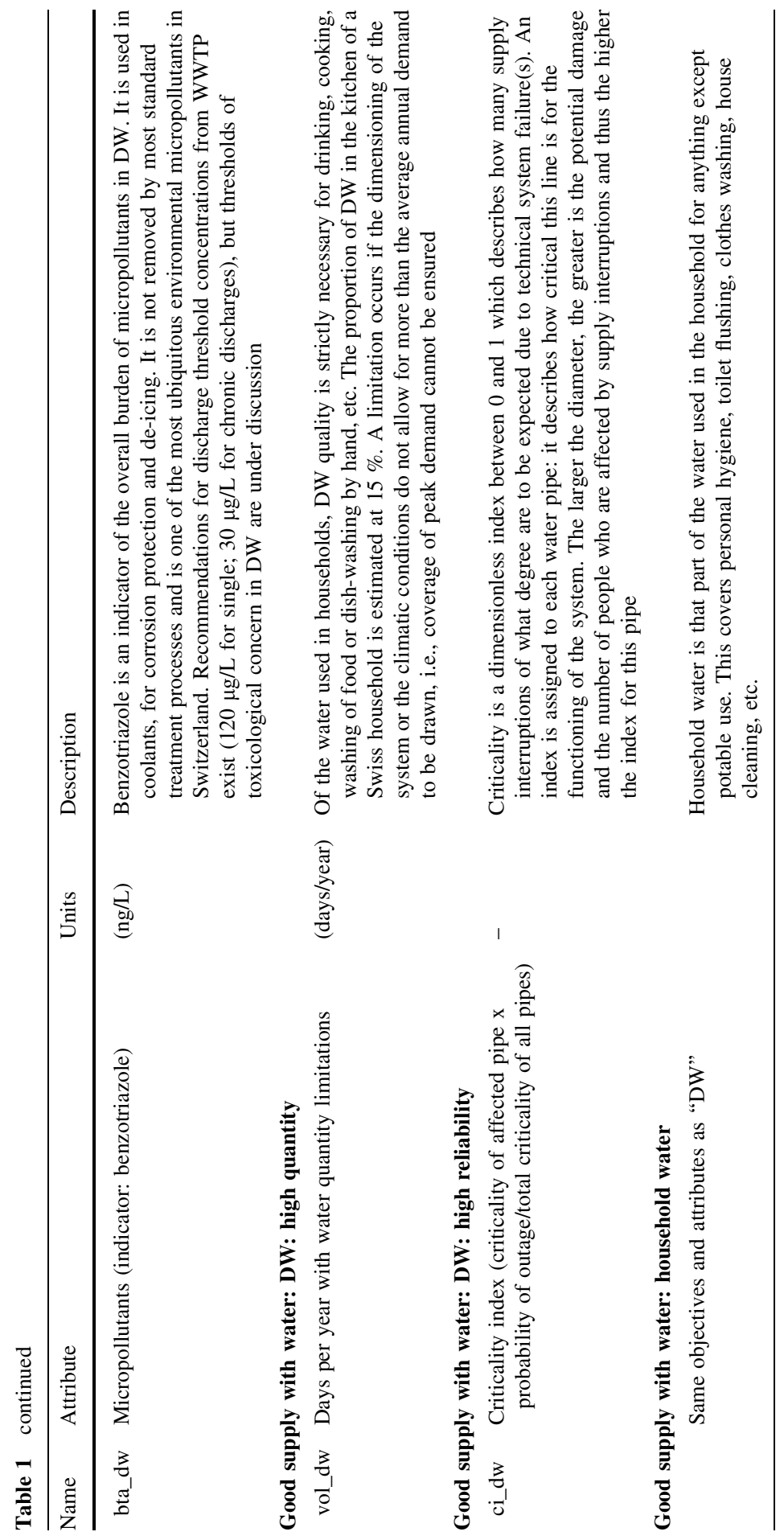




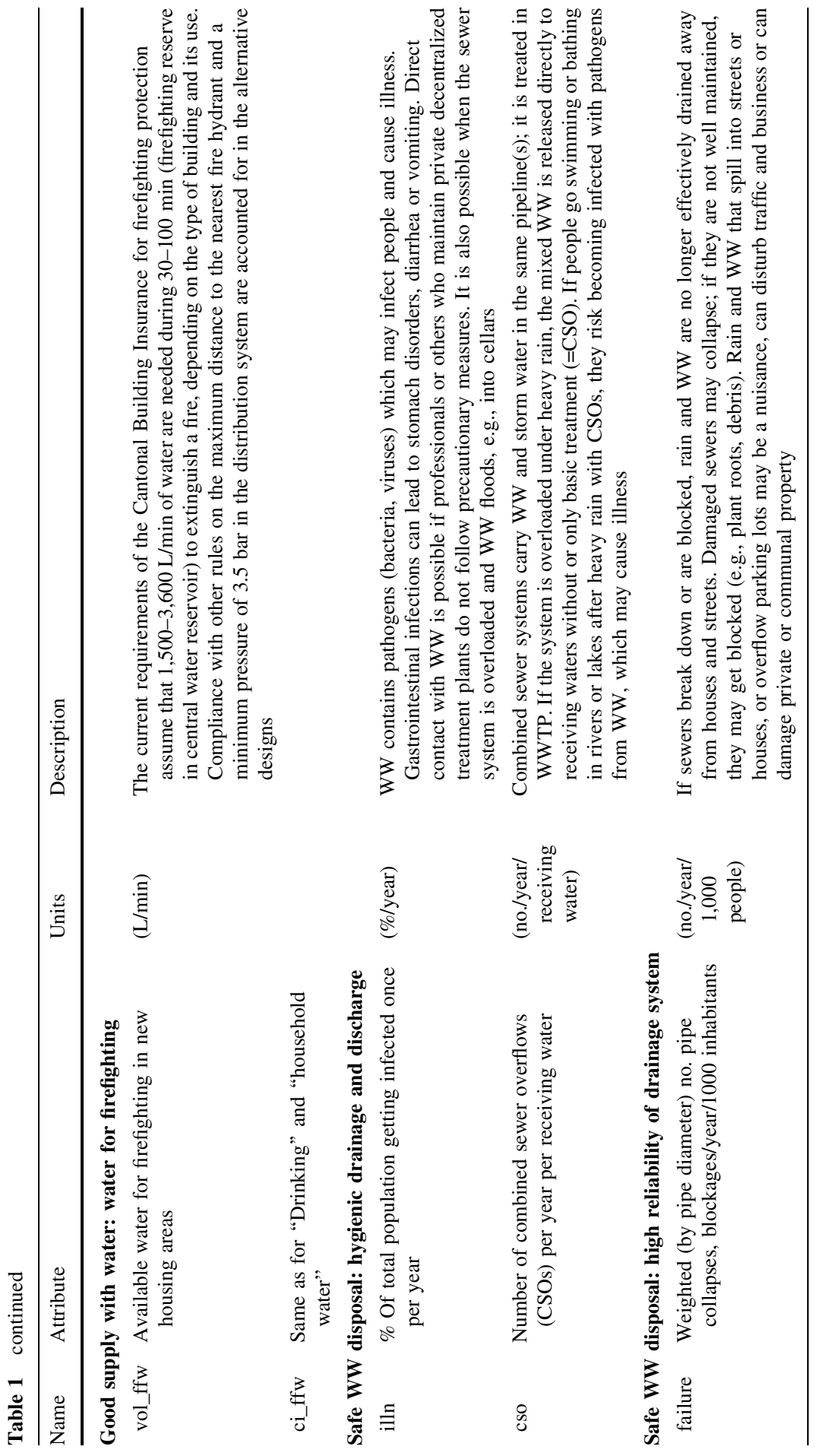




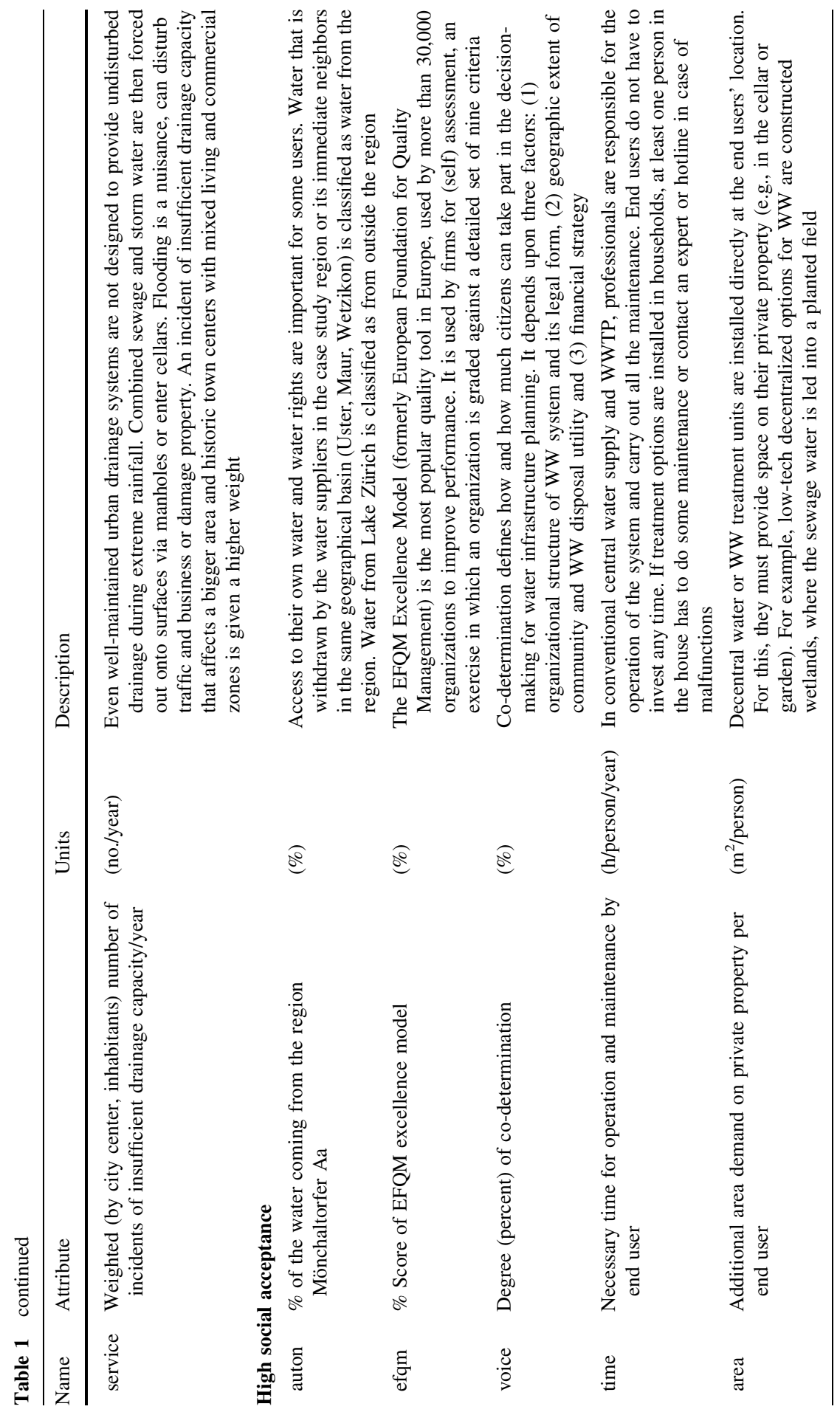




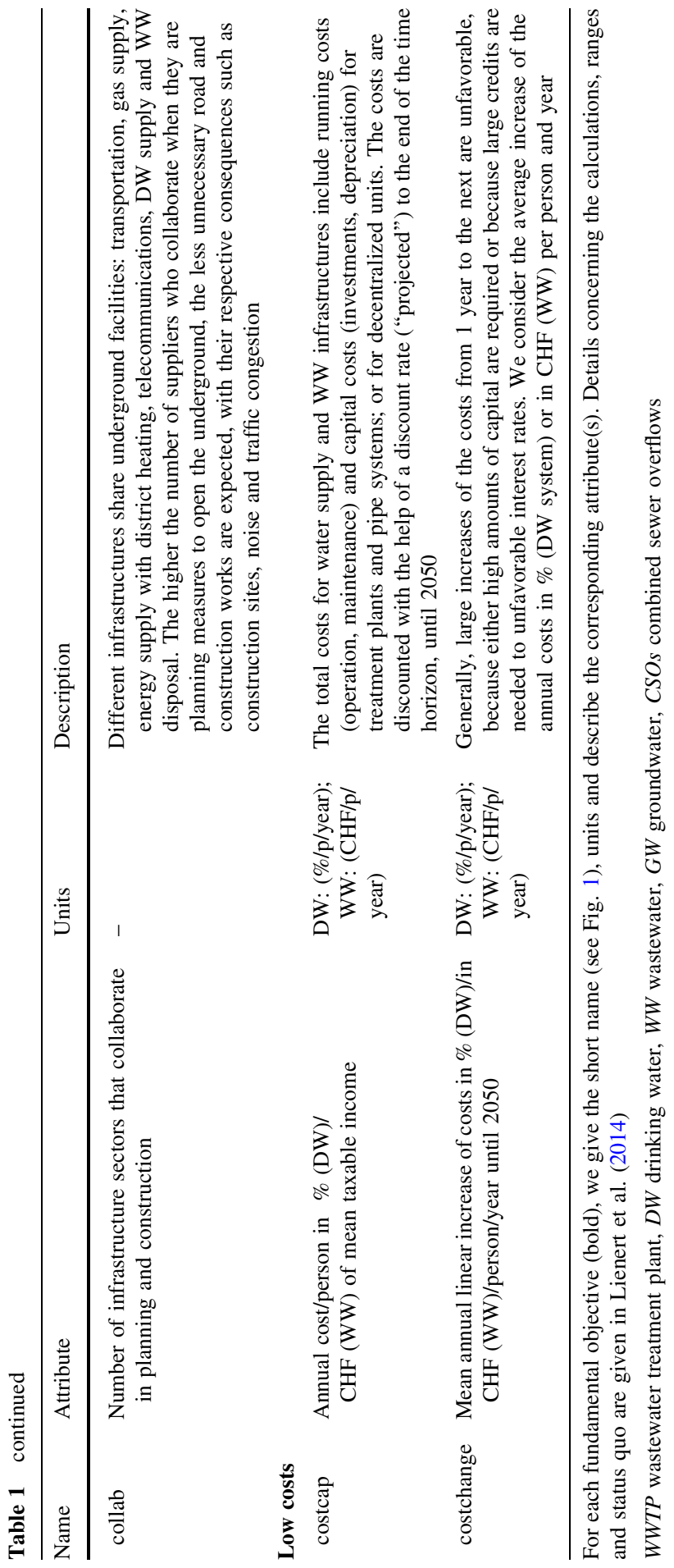


2050. They were discussed and adapted to the local case in three groups in which we ensured an equal distribution of perspectives. The specifications were based on a variation of eight factors relevant to water infrastructures. The scenarios were visualized, presented and discussed in the plenum (see Lienert et al. 2014). Finally, participants gave feedback in the plenum concerning: "Which development would I be happy about?" and "What did I learn?"

Three future scenarios were created in the workshop to characterize plausible socio-economic conditions in the "Mönchaltorfer Aa" region near Zurich in the year 2050. The "Boomtown Zurich Oberland" ("Boom") scenario was based on massive population growth and high prosperity. "Doom" depicted a difficult situation for Switzerland and Europe in the global world, with a slight population decline and few resources for the water sector. "Quality of life" assumed qualitative growth and emphasized sustainable development (Table 2; Lienert et al. 2014). The "status quo" scenario was not developed in the workshop; it is essentially a longterm projection of the current situation (i.e., current population, finances, etc.).

These scenarios provided valuable input, but needed further processing. For the "Boom" scenario with massive population growth (eight times the current population by 2050), the workshop participants presented spatial planning ideas (see Lienert et al. 2014). We later carried out quantitative and simplified spatial planning with two other NRP 61 projects, namely iWaQa (2013) and AGWAM (2013), to ensure better correspondence with likely urban expansion in Switzerland. ${ }^{8}$ We also modified the water demand (water usage/person/day). ${ }^{9}$

\subsection{Step (3): develop alternatives}

\subsubsection{General procedure to develop alternatives}

In simple decision problems, one often starts with defined alternatives; the SDM procedure then aims at choosing the best, but environmental management situations are not usually simple. The alternatives are often complex sets of actions that need to be created. The focus of SDM is then "all about the development of creative alternatives that are responsive to the defined objectives" (Gregory et al. 2012a). Good alternatives should be complete, comparable and value-focused (i.e., address key aspects), fully specified, internally coherent and distinct. Three basic steps are recommended: (1) brainstorm management responses, (2) organize these into fully specified alternatives and (3) refine them iteratively (Gregory et al. 2012a). We also recommend Eisenführ et al. (2010), Keeney (1992) and especially Clemen and

\footnotetext{
${ }^{8}$ We based the planning on Swiss standards, preserving agricultural land and forests. We used typical building features in dense areas of Swiss cities (Zurich, Geneva), with up to 10-storey houses, and allocated these to areas earmarked for urban development in the current spatial plans of the study region. We added additional building sites for the Boom scenario and increased the population to 200,000 without "building" skyscrapers.

9 The predictions for water demand are a function of scenario and alternative (e.g. water saving by using rain water or urine-separating toilets). Halving the water demand in the Doom scenario as defined in the workshop, for example, still translates into high water provision for the utilities, since there will likely be large water losses caused by low maintenance (leaky pipes).
} 
Table 2 Summary of four future scenarios for the year 2050

\begin{tabular}{|c|c|c|}
\hline Scenario & General characteristics & Water sector \\
\hline $\begin{array}{l}\text { Status Quo (as } \\
\text { 2010) }\end{array}$ & $\begin{array}{l}\text { 24,200 inhabitants in } 4 \text { rural } \\
\text { communities near Zürich } \\
\text { Extensive agriculture } \\
\text { Urban growth pressure } \\
\text { Lake for leisure activities, nature } \\
\text { protection zones } \\
\text { Eutrophication problems }\end{array}$ & $\begin{array}{l}\text { Fragmented water governance: } 3 \text { WWTP, } \\
\text { several water suppliers } \\
\text { High quality of DW } \\
\text { Water usage ca. } 215 \mathrm{~L} / \text { person/d (including } \\
\text { small businesses; only household water: } 135 \\
\text { L/person/d) } \\
\text { Insufficient water quality in rivers receiving } \\
\text { WW; contains micro- and other pollutants }\end{array}$ \\
\hline $\begin{array}{l}\text { (A) Boomtown } \\
\text { Zürich } \\
\text { Oberland }\end{array}$ & $\begin{array}{l}\text { Highly prosperous region } \\
200,000 \text { inhabitants } \\
\text { Dense urban development } \\
\text { Lake Greifensee is nature } \\
\text { protection zone } \\
\text { New transportation axes (magnetic } \\
\text { levitation train) }\end{array}$ & $\begin{array}{l}\text { High-tech water treatment, new technologies } \\
\text { (on-site) } \\
\text { Overall increased water demand, but lower per } \\
\text { person usage }{ }^{c} \\
\text { DW quality like today's } \\
\text { WW quality higher than today (remove } \\
\text { micropollutants) }\end{array}$ \\
\hline (B) Doom & $\begin{array}{l}\text { Switzerland and Europe lose } \\
\text { attractiveness, globally } \\
\text { Strong financial pressure on water } \\
\text { infrastructures } \\
\text { Slight population decline } \\
\text { Strong urban sprawl } \\
\text { Decline of industries } \\
\text { Communities have to collaborate }\end{array}$ & $\begin{array}{l}\text { High DW demand }{ }^{\mathrm{c}} \text { (162 liter/person/day } \\
\text { household use; }-25 \% \mathrm{WW} \text { discharge) } \\
\text { Very bad state of infrastructures } \\
\text { Population uses own sources (bottled water, rain } \\
\text { water) } \\
\text { Increasing environmental effects due to low } \\
\text { WW treatment } \\
\text { Deficient urban drainage; climate change effects } \\
\text { (flooding) }\end{array}$ \\
\hline $\begin{array}{l}\text { (C) Quality of } \\
\text { life }\end{array}$ & $\begin{array}{l}\text { Highly prosperous region } \\
\text { Moderate population growth } \\
\quad(<5 \% / \text { year, until } 2050 \mathrm{ca} \text {. } \\
\quad+20 \%=29,000) \\
\text { Only } 5 \% \text { new building areas } \\
\text { Good financial situation } \\
\text { High environmental and health } \\
\text { awareness }\end{array}$ & $\begin{array}{l}\text { Higher DW quality } \\
\text { Lower water demand per person }{ }^{\mathrm{c}} \\
\text { Public network, rain retention basins, advanced } \\
\text { treatment ponds } \\
\text { Very high quality standards for WW treatment } \\
\text { Nutrient reuse from WW }\end{array}$ \\
\hline
\end{tabular}

For details, see Lienert et al. (2014)

$W W T P$ wastewater treatment plant, $D W$ drinking water, $W W$ wastewater

a The communities are: Egg, Gossau, Grüningen and Mönchaltorf

b $215 \mathrm{~L}$ water usage/person/day based on average water consumption for households and small businesses from 2008 to 2011 in case study communities. In the alternatives, we based our consumption estimations in households on statistical data from Switzerland and Austria (see attribute description in Lienert et al. 2014)

c Although some groups defined the exact water amount per person and day for their scenario, we did not use these, because water usage also depends on the alternatives and because we based later calculations on different assumptions for the "Doom" scenario (see Methods)

Reilly (2001) for creativity techniques. These include idea checklists, Osborn's 73 idea-spurring questions (Osborn 1963), strategy generation tables (Howard 1988), metaphorical thinking and many more approaches. 
"Morphological forced connection" is a creativity technique in which various factors characterizing a problem are brainstormed (e.g., financial strategy) and various specifications are listed under each factor (e.g., constant budget, progressive budget, ...; Clemen and Reilly 2001). Combinations and permutations are then tried out. A "strategy generation table" (Howard 1988) is a more rigorous variant, in which each decision alternative (=strategy) consists of exactly one chosen specification for each factor, which are combined. It is a good framework for easily screening all imaginable combinations for useful candidates. Examples come from business problems or a NASA space-exploration mission (see Clemen and Reilly 2001 and references therein). Strategy generation tables are especially well suited for environmental management problems (e.g., Gregory et al. 2012a, b).

\subsubsection{Procedure applied in the SWIP application example}

In our application example, we used a strategy generation table to create alternatives in the second stakeholder workshop in May 2011. We used the four socio-economic scenarios from the first workshop as a background. Note that this was not necessary for the MCDA, since we analyzed the performance of all alternatives for all scenarios; it was just a way to stimulate creativity. We prepared the strategy generation table beforehand (see Lienert et al. 2014). The 17 factors, which consisted of various specifications, concerned the organizational structure, geographic extent, financial strategy, construction and operation of the infrastructure and system technology for wastewater and drinking water. The 20 participants were split into four mixed groups and assigned to a specific scenario. Each of them created at least two strategic alternatives by choosing a plausible specification for each factor. These backbones were used by the project team to develop detailed and internally consistent alternatives (for feedback, see Sect. 2.2.2).

Ten strategic decision alternatives were created in the stakeholder workshop (Table 3). These were combinations of various technical infrastructure options (e.g., central vs. decentralized treatment), maintenance and rehabilitation strategies (e.g., continuous replacement vs. no rehabilitation) and management aspects (e.g., public vs. privatized organizational forms). After the workshop, we specified the alternatives and ensured internal coherence. We had to create some new factors to distinguish between alternatives: these specified the detailed water and wastewater treatment technologies and several characteristics regarding organizational activities and quality enablers to assess the "\% score of EFQM Excellence Model" attribute (Table 1). Narratives for each alternative based on the stakeholders' inputs and the factor specifications are given in Lienert et al. (2014). We also developed some additional variants, especially based on the status quo.

\subsection{Feedback about the SDM procedure}

We collected stakeholder feedback at each step of the SDM procedure and used this to critically analyze the main advantages and disadvantages of each step and to give recommendations (Table 4; for details, see Lienert et al. 2014). 
Table 3 Summary of strategic decision alternatives (see Lienert et al. 2014)

\begin{tabular}{|c|c|c|}
\hline No. & Alternative name & Description \\
\hline A1a & $\begin{array}{l}\text { Centralized, privatization, high } \\
\text { environmental protection }\end{array}$ & $\begin{array}{l}\text { Private firm provides full centralized service for entire } \\
\text { region; service as today but with micropollutant removal } \\
\text { at WWTP (high environmental protection) }\end{array}$ \\
\hline A1b & Centralized, IKA & As A1a, but provider is intercommunal agency (IKA) \\
\hline A2 & Centralized, IKA, rain-stored & $\begin{array}{l}\text { Intercommunal agency (IKA) provides full centralized } \\
\text { service, but rain is stored for firefighting }\end{array}$ \\
\hline A3 & Fully decentralized & $\begin{array}{l}\text { Fully decentralized system in the responsibility of } \\
\text { households with collection of rain water, bottled water } \\
\text { from supermarket, and re-use of graywater }\end{array}$ \\
\hline A4 & $\begin{array}{l}\text { Decaying infrastructure, } \\
\text { decentralized in outskirts }\end{array}$ & $\begin{array}{l}\text { Mixed responsibilities with minimal community service; } \\
\text { decaying central infrastructures in core area, } \\
\text { decentralized in outskirts; drinking water with POU } \\
\text { systems, or bottled water }^{\mathrm{a}}\end{array}$ \\
\hline A5 & $\begin{array}{l}\text { Decaying infrastructure } \\
\text { everywhere }\end{array}$ & $\begin{array}{l}\text { Community provides minimal service; cheap decentralized } \\
\text { infrastructure in responsibility of households (as in } \\
\text { outskirts of A4) }\end{array}$ \\
\hline A6 & Maximal collaboration, centralized & $\begin{array}{l}\text { Maximal collaboration in a cooperative that provides full } \\
\text { centralized service; micropollutant removal at WWTP; } \\
\text { strong focus on storm water retention }\end{array}$ \\
\hline A7 & $\begin{array}{l}\text { Mixed responsibility, fully } \\
\text { decentralized with onsite } \\
\text { treatment }\end{array}$ & $\begin{array}{l}\text { Cooperative and private responsibility; full } \\
\text { decentralization; re-use of treated rainwater at POE; on- } \\
\text { site wastewater treatment; nutrient recovery for } \\
\text { agriculture; storm water retention as } \mathrm{A} 6^{\mathrm{b}}\end{array}$ \\
\hline A8a & $\begin{array}{l}\text { Status quo with storm water } \\
\text { retention }\end{array}$ & Status quo with storm water retention \\
\hline $\begin{array}{l}\mathrm{A} 8 \mathrm{~b}- \\
\mathrm{A} 8 \mathrm{f}\end{array}$ & Status quo technical variants & Status quo is modeled with different technical variants \\
\hline A9 & $\begin{array}{l}\text { Centralized, privatization, minimal } \\
\text { maintenance }\end{array}$ & $\begin{array}{l}\text { Consumers choose private contractor that seek revenue } \\
\text { maximization; fully centralized system; minimal repairs } \\
\text { only upon urgent need for action }\end{array}$ \\
\hline
\end{tabular}

WWTP wastewater treatment plant

a $P O U$ Point of use treatment in households to achieve drinking water quality; can be done, e.g., on the tabletop or under the sink

b $P O E$ Point of entry (e.g., water treated close to where it enters household; at entry point from centralized water system or after water storage tank)

\section{Discussion}

In this paper, we developed a thorough participatory procedure to support infrastructure planning processes in the water sector. Based on a real case study in Switzerland, we demonstrated how the initial steps of SDM (Gregory et al. 2012a) can be carried out. Below, we compare our application with the general SDM procedure. We discuss the main advantages and disadvantages (Table 4; details in Lienert et al. 2014) before drawing conclusions. 
Table 4 Summary of recommendations for the steps of the SDM process, including advantages and disadvantages, based on own experience and stakeholder feedback

\begin{tabular}{|c|c|c|c|}
\hline Step & Recommendation & Advantage & Disadvantage \\
\hline
\end{tabular}

1. Clarify decision context

1.1 Case study selection and delimitation of system boundaries

Choose "real problem", i.e. SH need a High willingness of SH to solution

Clearly define interactions (type, number, length); look for support by important SH (as mediators)

Strong commitment of researchers participate

Increase willingness to participate

Better knowledge of case study

\subsection{SH selection; clarify decision problem with $\mathrm{SH}$}

Stratified sampling (e.g., vertical axis: from local to national/horizontal: engineering, administration, politics)

Face-to-face interviews (e.g., who plays role, is affected, interactions, interests, objectives)

(specific: treat $\mathrm{SH}$ w. respect/guideline/ creativity/feedback/simple language/ avoid scientific terms)

$\mathrm{SH}$ selection with short questionnaire (Email, phone, internet survey): Who is important/affected? Interests?

SH selection with snowball sampling: Who else should we include? Who has very different view?

Ask for SH expectations (e.g., what is next step/by whom? Expectations/ hopes/fears/recommendations?)

Clear communication/information material about type of results and which expectations are/are not met

2. Define objectives and attributes

2.1 Set up objectives on desktop by research team, e.g., based on engineering requirements/ sustainability goals

Face-to-face interviews; e.g., first open question ("what is fundamental?"); then consolidate w. existing objectives

Ensures broad coverage of $\mathrm{SH}$

Good representation of different perspectives

In-depth knowledge about SH (e.g., interests, problems, interactions)

\section{Much faster procedure}

Broader (representative) coverage

Include specific

knowledge of $\mathrm{SH}$

Include extreme perspectives

Clarification: often $\mathrm{SH}$ expect practical outcomes (e.g., tool)

Avoids later disappointment if $\mathrm{SH}$ expect other outcomes

Objectives comply with methodol.

requirements $\mathrm{a} /$ state-ofthe-art

Avoids priming effects

Focus on ideas/objectives of $\mathrm{SH}$
Case study $\neq$ scientific project

Lower flexibility to adapt to changes

Mediators can be difficult to identify

High time demand

Less obvious SH might be missed out

Very time consuming (costly)

Unrepresentative sample

Loss of in-depth

knowledge

Staying very close to initially chosen $\mathrm{SH}$ : all belong to same system

Asking may lead to disappointment if expectations are not met Risk of disappointing $\mathrm{SH}$ at the start of the project

Loss of local SH knowledge

Objectives may not meet $\mathrm{SH}$ needs

Risk: too many/diverging objectives

Risk: ignore methodol. requirem $^{\mathrm{a}}$ 
Table 4 continued

\begin{tabular}{ll}
\hline Step & Recommendation \\
\hline $2.2 \quad \begin{array}{l}\text { Generate/discuss/consolidate } \\
\text { objectives in workshop (e.g., } \\
\text { brainstorming or present objectives } \\
\text { from } 2.1 \text {; discuss w. neighbor; } \\
\text { discuss in plenum to seek consensus; } \\
\text { use moderation methods to reduce } \\
\text { number) }\end{array}$
\end{tabular}

Advantage Disadvantage

Ideally, reflection of all opinions

Better understand other SH opinions

Bilateral gives voice to shy $\mathrm{SH}$

Ideally, focus on fundamental obj.

\subsection{General recommendations for objectives and attributes ${ }^{\mathrm{b}}$}

Understandability: Use attributes common in field (weighting by all $\mathrm{SH}$; elicit value function from experts)

Missing or irrelevant objectives: Generate objectives with intensive SH interaction (see 2.1, 2.2 above)

Attribute ranges: define generalizable attributes; use relative numbers (absolute numbers for case study example; elicitation: avoid "range effect" bias)

Preferential independence: try to fulfill; check validity ("do preferences depend on levels of other attributes?")

Minimum criteria: some SH insist on minimal requirements, e.g., laws; discuss implication with $\mathrm{SH}$

Develop future scenarios

Capture future uncertainty w.r.t. socio-economic development with snap-shot images. Must be very well prepared and moderated; convey that it is real science!

3. Identify and create decision alternatives ${ }^{\mathrm{c}}$

SH workshop using creativity technique; e.g., create storylines of alternatives with scenarios as background
Based on scientific evidence

Generalizable to other cases

If $\mathrm{SH}$ regards objective as irrelevant: give weight of zero

Allows for up- or downscaling in other case studies

If this holds: simple additive aggregation model may be used

Easy implementation in MCDA with minimum aggregation model

Highly stimulating, very creative, fun

Creates team feeling; raises interest

Invites thinking broadly about future

Alternatives are relevant to $\mathrm{SH}$

Reduces anchoring on status quo
Risk: objectives cannot be deleted

Risk: no shared opinion

Risk: ignore methodol. requirem $^{\mathrm{a}}$

Risk: lose control (moderation!)

Technical/natural-scientific attributes difficult for nonexpert $\mathrm{SH}$

Missing objectives cannot be added later; test sensitivity to this objective

Large ranges may be unrealistic

Relative numbers may be less tangible/more difficult to understand

If not given: more complex models needed (e.g., multiplicative)

Strong implications: exclusion of all alternatives not meeting minimum

Risk: not dealing with real problems

Only limited participants possible

Risk that things get out of control

Alternatives are not well worked-out: require further processing for MCDA 
Table 4 continued

\begin{tabular}{llll}
\hline Step & Recommendation & Advantage & Disadvantage \\
\hline & $\begin{array}{l}\text { Combine creativity (above) with } \\
\text { rigorous } \\
\text { technique; e.g., strategy } \\
\text { generation table } \\
\text { (with/without SH participation) }\end{array}$ & $\begin{array}{c}\text { All important elements are } \\
\text { covered } \\
\text { Internal consistency of } \\
\text { alternatives }\end{array}$ & $\begin{array}{c}\text { Not very creative; tedious } \\
\text { work }\end{array}$ \\
& & $\begin{array}{c}\text { Rather time-consuming } \\
\text { procedure }\end{array}$ \\
\hline
\end{tabular}

For details, see Lienert et al. (2014)

SH stakeholders

a Objectives should comprehensively cover the decision, be fundamental, complete, concise, sensitive (distinguish between alternatives), non-ambiguous, understandable, simple, non-redundant and be preferentially independent (to allow for an additive value model). Based on feedback from later MCDA interviews for preference elicitation, not all requirements were met for all SH; see Lienert et al. (2014)

b Based on feedback mentioned in ${ }^{\mathrm{a}}$

c Feedback concerning hypothetical alternatives and trade-off questions required in MCDA preference elicitation, see Lienert et al. (2014)

\subsection{Step (1): clarify the decision context}

In environmental management, a single solution is commonly sought to a pressing problem. However, other decision types might also be pursued, such as "linked choices" or a ranking of risks (Gregory et al. 2012a). Decisions will sometimes be repeated and an efficient, defensible decision system needs to be established. The SDM framework developed here to support sustainable water infrastructure planning (SWIP 2014) belongs to this type. The SWIP approach must be transferable to other cases and accepted by the stakeholders involved. This is why we stressed the first structuring steps of the SDM process so much.

Selecting stakeholders is tricky even with the systematic approach that we followed. Gregory et al. (2012a) also acknowledge that it can be surprisingly difficult to identify the decision makers. Even in one-off governmental (environmental) decisions, stakeholders other than the official representatives may have to be involved. It is usually unclear whether the participants of the SDM process (Gregory et al. 2012a suggest five to twenty-five people) represent society in general at all well; these are often people with strong interests in the outcomes. We think that the general SDM process of Gregory et al. (2012a) can benefit from integrating tools for systematic stakeholder selection to ensure good representation. We exemplified this in our SWIP project with a detailed stakeholder and social network analysis (see Lienert et al. 2013 and references therein). This was based on 27 faceto-face interviews that lasted $2-4 \mathrm{~h}$ each. In our case, therefore, stakeholder characterization was linked to extensive effort, which absorbed over a year of the work of a PhD student (to set up interview guidelines, find suitable participants, organize, carry out and transcribe interviews and analyze data). In most practiceoriented SDM applications, we think that a short questionnaire among actors will suffice to ensure a fair representation of different perspectives (Table 4; details in Lienert et al. 2014). However, this still entails more effort than proposed by Gregory et al. (2012a). 
Selecting the case study in research projects is typically driven by scientific considerations and less by the need to solve a real-world problem (Renner et al. 2013). Although this also applied to our SWIP example, it is problematic because it can hinder later collaboration with stakeholders (Table 4; Lienert et al. 2014). In our case, we invested considerable time to convince stakeholders to collaborate. We had to rely on their goodwill to give us access to data or to participate in interviews after regular working hours. We, therefore, strongly recommend choosing a "real problem" as an application, also in scientific projects. To increase the willingness to participate, we recommend defining the type, number and length of interactions. Moreover, the expectations of stakeholders often differ from what science can typically offer (e.g., Lang et al. 2012; Renner et al. 2013). For example, some of our interview partners expected a simple decision tool for infrastructure planning, which we cannot develop as part of this project (Table 4). To avoid disappointment, it is essential to ask about expectations and communicate the results that can or cannot be provided from the start.

\subsection{Step (2): define objectives and attributes}

In the SWIP example, it was extremely time-intensive to generate the objectives hierarchy. In the first desktop top-down procedure (Clemen and Reilly 2001), the objectives were discussed in the monthly meetings of the scientific project team and intermittently processed during a year. The main advantage of this top-down approach is that we are sure that the objectives meet the engineering as well as SDM requirements, i.e. invalid objectives are avoided and there is no double counting (see Sect. 2.2; Table 4; details in Lienert et al. 2014).

We judge our approach to consider individual stakeholder perspectives in faceto-face interviews as highly beneficial (see Sect. 2.2, also concerning time requirement). Personal viewpoints can then be included on an equal footing with consensus opinions. Priming effects can be avoided using open questions. Interviews are not commonly used to generate objectives. Creative brainstormingtype stakeholder workshops, as recommended by Gregory et al. (2012a), are usually described in the literature. The advantage of workshops is that fast agreement is possible (in our case $5 \mathrm{~h}$ for the workshop plus a few days preparation). Structuring tools can support the workshop and visualization with, e.g., means-ends networks is recommended (also see Clemen and Reilly 2001 and Sect. 2.2). However, workshops risk missing fundamental aspects because of a premature consensus (the famous "groupthink" phenomenon"-Janis 1972; 1982; see, e.g., review by Kerr and Tindale (2004)).

The generation of good attributes applicable to other cases again took up several months of intermittent PhD student work. We had to use some "proxy attributes", which are preferably avoided (see Sect. 2.2), but often found "natural attributes" based on engineering considerations. The integration of environmental and societal objectives with traditional technical and economic indicators is a recent development in engineering (e.g., Ashley et al. 2008; Balkema et al. 2001; Lundie et al. 2004; Palme et al. 2005). We hope to contribute to it by presenting our attributes in detail (Table 1; details in Lienert et al. 2014). We additionally focused on the 
formal requirements for objectives according to decision theory, which may have been less familiar to engineering approaches, such as LCA. To make the proxy as well as the natural attributes more tangible, we combined them with narratives relating to the status quo and the best- and worst-possible cases (Lienert et al. 2014), as recommended by (Gregory et al. 2012a). This was especially useful for the later elicitation of stakeholder preferences for the MCDA (Scholten et al. 2014b; Zheng et al. 2014). We generalized the attributes wherever possible; e.g., the attribute of "good chemical state of watercourses" was set up together with the iWaQa project (2013) and covers the worst- and best-possible general case of water quality indicators (Schuwirth et al. 2012). Similarly, "recovery of nutrients" from wastewater covers the whole range from 0 (as today) to $100 \%$ (e.g., urine source separation and fecal collection; Larsen et al. 2009, 2012).

The aim of the SWIP project to build a comprehensive, generalizable objectives hierarchy contrasts with the condition of conciseness (e.g., Belton and Stewart 2003; Clemen and Reilly 2001; Eisenführ et al. 2010; Gregory et al. 2012a; Keeney 1992; Keeney and Raiffa 1976). Gregory et al. (2012a) propose using only six to ten objectives, because people cannot keep track of more. If more seem necessary, the objectives can be grouped into sub-objectives. We did this and built objectives hierarchy with only six top-level objectives (Fig. 1). Gregory et al. (2012a) further recommend context-specific rather than universal-usage objectives. The SWIP objectives hierarchy proposed here (Table 1) is a compromise, since the aim is to support different, but specific decisions in water infrastructure planning rather than general water management decisions. We encourage the use of our SWIP objectives hierarchy, but advise others to carefully discuss the exclusion of objectives that are irrelevant to their specific application. Moreover, the attribute ranges (Lienert et al. 2014) need to be adapted to other alternatives and system boundaries. If natural attributes are available in cases where we used proxies, these should be chosen instead.

\subsection{Future scenarios}

Scenario planning (e.g., Ringland 2002; Schnaars 1987; Schoemaker 1995) is not a standard part of MCDA or SDM, but is recommended by Gregory et al. (2012a) to structure situations where it is difficult to assign probabilities. We found the combination of SDM with scenario planning highly fruitful. In our case study, the scenario workshop was the event that was the most fun for stakeholders. For example, one participant stated that: "It's great to step back from daily routine, question the current system and let your imagination run freely to think about the world in 2050". We made similar observations in other scenario workshops (Lienert et al. 2006; Störmer et al. 2009; Truffer et al. 2010). We recommend stimulating workshops to get people "on board" and create a good project feeling. A risk of having fun is to imply that the project does not deal seriously with the stakeholder's problems (Table 4; Lienert et al. 2014). So it is important to moderate workshops carefully. Workshops can host only few participants, but have the advantage of generating results quickly. In our case, we invested a few days in preparing the 5-h workshop. However, the $\mathrm{PhD}$ students needed around another 4-5 weeks to specify 
the Boom scenario in particular, which needed extensive "building" of new infrastructure. This was necessary for the following MCDA, but is not required if SDM is used only for structuring.

Scenario planning has recently entered the MCDA literature. This tool is designed to capture substantial external (scenario) uncertainties for strategic decision-making. In our project, we followed Goodwin and Wright (2001), who assume that the decision makers' preferences do not change with respect to different futures. Hence, each stakeholder's preferences are elicited only once for the MCDA, instead of once for each scenario (e.g., Karvetski et al. 2009, 2011; Lambert et al. 2012; Montibeller et al. 2006; Ram and Montibeller 2013; Ram et al. 2011; Stewart et al. 2013). We argue that we have to make decisions (about water infrastructures) today. These are grounded in the given state of the world, our subjective preferences and our ideas about the future. The preferences of each stakeholder include a subjective view about current conditions and a likely future. We emphasize that these individual future views are not captured by the scenarios: they do not contain a prediction $^{10}$ of what will happen, nor of the stakeholder's implicit beliefs. ${ }^{11}$ If we use consistent preferences, we must ensure that the range of each attribute spans the entire possible (but uncertain) outcome for all scenarios (e.g., Stewart et al. 2013; ranges see Lienert et al. 2014). Thus, MCDA modeling efforts increase because we estimate the performance of each alternative for each attribute with respect to all four scenarios.

\subsection{Step (3): develop alternatives}

There are many ways to creatively generate alternatives (see Sect. 2.4). In our application, we combined a desktop approach with a stakeholder workshop. This ensured that stakeholders understand our methods in that alternatives are relevant to them and that they are subsequently better accepted (Gregory et al. 2012a). It also avoids overlooking issues obvious to local practitioners. We also found the combination of the "strategy generation table" (Gregory et al. 2012b; Howard 1988) with scenarios as background to be highly effective. In decision-making, there is a very strong tendency to anchor on status quo alternatives (Nutt 2004). We thus expected stakeholders to create conventional infrastructure alternatives under "Status Quo", while the "Boom" scenario triggered high-tech on-site solutions and the "Doom" scenario cheap and simple alternatives (Lienert et al. 2014). The strategy generation table then forced participants to rigorously cover the main elements, thus contributing to the basic requirements of the alternatives, i.e. internal consistency, completeness and comparability (e.g., Gregory et al. 2012a; Keeney and Raiffa 1976). The strategy generation table addresses this well, but has the drawback of involving tedious work. We thus recommend generating storylines in a

\footnotetext{
10 "Second, scenario analysis usually tries to identify a set of possible futures, each of whose occurrence is plausible but not assured. This combination of offering more than one forecast, and offering it in form of a narrative, is deemed by advocates to be a more reasonable approach than trying to predict (to four significant decimal places) what will happen in the future" (Schnaars 1987, p. 106).

${ }^{11}$ The sum of the probabilities for the realization of the scenarios is not 1 but can be anywhere between 0 and 1.
} 
creative stakeholder process, but letting the project team provide the factor specifications (Table 4; Lienert et al. 2014). The time demand was similar to the scenario workshop: preparation took a few days, but the PhD students invested 3-5 weeks thereafter to specify the detailed alternatives for the MCDA.

A further advantage of the strategy generation table is that it allows for fast screening of all imaginable strategies (Clemen and Reilly 2001). Thus, it is possible to check whether each cell in the table is reflected in an alternative. This was mostly the case in our SWIP example (Lienert et al. 2014). It is recommended to iteratively improve or create new alternatives in SDM processes (Gregory et al. 2012a). An important advantage of MAUT (contrary to outranking procedures) is that alternatives can easily be added later (e.g., Keeney and Raiffa 1976).

Moreover, in our SWIP application, feedback from later MCDA interviews indicated that some stakeholders had difficulties in formulating preferences about unconventional alternatives (e.g., fully decentralized wastewater disposal; e.g., Guest et al. 2009; Larsen et al. 2009, 2012; Libralato et al. 2012). Gregory et al. (2012a) discuss the opposite problem, namely that stakeholders suggest alternatives which experienced environmental managers know to be unfeasible. They recommend including all proposed alternatives and using iteration in the SDM workshops to check how well they perform. We followed this recommendation in our example and included all alternatives in the later MCDA. However, in the later interviews for preference elicitation, we explained the reasons for including unconventional alternatives; e.g., to provide general insights that go beyond the daily problems covered by the case study (Scholten et al. 2014b; Zheng et al. 2014).

\section{Conclusions and outlook}

From the initial SDM structuring steps (Gregory et al. 2012a) applied to the SWIP case study, we can learn that the fundamental objectives of "good water supply" and "safe water disposal" (Fig. 1) were undisputed among the stakeholders. Feedback from interviews and workshops indicates that "intergenerational equity" and "high social acceptance" seem less important. Alternatives involving privatization or mergers (A1, A2; Table 3) perform especially well with respect to the "high quality of management and operations" and could help overcome deficiencies due to the current fragmentation of the Swiss water sector (Dominguez et al. 2011; Lienert et al. 2013). Thus, the conventional solution (A8) may dominate alternatives A1 or A2. Negative aspects of decentralized solutions (time and area demand for end users; e.g., A3, A4, A5, A7) are also characterized by objectives of "high social acceptance"; if these are not important, they could perform well. On the other hand, a positive aspect of decentralized alternatives is their flexibility: if "intergenerational equity" is unimportant, flexibility has little positive effect. Thus, we cannot conclusively dismiss decentralized alternatives at this stage, especially since their performance also depends on the scenario. A further analysis must follow the initial structuring phase.

In our case, we combine the SDM framework with more quantitative MAUT analyses (e.g., Belton and Stewart 2003; Eisenführ et al. 2010; Keeney and Raiffa 1976). Models are developed in our SWIP project that predict the performance and 
decay of water supply and wastewater systems (Egger et al. 2013; Scheidegger et al. 2011, 2013; Scholten et al. 2013, 2014a). We elicited stakeholder preferences in second interviews (weights, single-attribute value functions, aggregation schemes, risk attitudes) and are currently carrying out MAUT analyses (Scholten et al. 2014b; Zheng et al. 2014). In this way, we hope to identify one or several robust alternatives that perform well for most stakeholders in all future scenarios.

Adding a formal MCDA to the SDM structuring process is one option. Obviously, our thorough SDM procedure comprising "only" the initial steps is lengthy and expensive. In many cases, it may suffice to explore important issues by relying on elements of our work, which is why we present more details in Lienert et al. (2014). For example, our objectives hierarchy (Fig. 1) and our strategic decision alternatives (Table 3) could be adapted in further analyses. New alternatives can easily be created with the strategy generation table (Lienert et al. 2014). An engineering firm might estimate the performance of the decision alternatives on the basis of our attributes (Table 1). Once this information is available, more resources may be put into the most promising alternatives.

We strongly encourage environmental managers to consider the SDM approach (Gregory et al. 2012a). Setting up difficult decision problems along the initial SDM steps will help them to better structure their case. We are convinced that it will prove to be highly useful to carefully think about: (1) delimiting the problem and defining stakeholders, (2) discussing what one actually wants to achieve, and (3) coming up with creative ideas of how these objectives can be achieved. We regard this as useful even if no quantitative MCDA evaluation follows to support decisionmaking, but for instance a scientific risk assessment or a cost-benefit analysis. Structuring the decision along the proposed lines will help to avoid overlooking important stakes and uncertainties, will clarify the nature of the trade-offs that have to be made, and will open-up thinking to allow for more imaginative and better defensible solutions.

We hope to contribute to MCDA, but also to real decision-making with this work. Hopefully, we can provide some guidance to engineers or community planners who are confronted with the "daunting challenge" (Milly et al. 2008) — in the face of an increasingly uncertain future-of finding sustainable solutions for safe water supplies and wastewater disposal, which are of vital importance to us all.

Acknowledgments We thank the Swiss National Science Foundation for funding within the National Research Program entitled "Sustainable Water Management" (NRP 61; www.nfp61.ch), Project Number: 406140_125901/1. We thank Cristina Fritzsche, Peter Reichert, Florian Schnetzer, Jun Zheng and Anja Zorn for their good collaboration and data collection, and the interview partners and workshop participants for their patience, support and valuable input. We thank Richard Michell for improving our English. We also thank two anonymous reviewers and the editors for their critical reviews which helped to greatly improve the manuscript.

\section{References}

AGWAM (2013) Increasing water scarcity, also for Swiss agriculture. Project of the National Research Program NRP 61. http://www.nfp61.ch/E/projects/cluster-water-management/water_agriculture/ Pages/default.aspx. Accessed 06 December 2013 
Arnbjerg-Nielsen K, Fleischer HS (2009) Feasible adaptation strategies for increased risk of flooding in cities due to climate change. Water Sci Technol 60(2):273-281

Ashley R, Blackwood D, Butler D, Jowitt P, Davies J, Smith H, Gilmour D, Oltean-Dumbrava C (2008) Making asset investment decisions for wastewater systems that include sustainability. J Environ Eng ASCE 134(3):200-209

AWEL (2003) Amt für Abfall, Wasser, Energie und Luft, Kt. Zürich (Office for waste, water, energy, and air, ct. Zürich). Phosphorbelastung des Greifensees; in German (Phosphorus pollution of Lake Greifensee). http://www.awel.zh.ch/internet/baudirektion/awel/de/wasserwirtschaft/gewaesserqualitaet/ seen_kenngroessen.html. Accessed 06 December 2013

AWEL (2006) Amt für Abfall, Wasser, Energie und Luft, Kt. Zürich (Office for waste, water, energy, and air, ct. Zürich). Zustand der Fliessgewässer in den Einzugsgebieten von Glatt und Greifensee; Messkampagne 2004/2005; in German (State of watercourses in the catchments of Glatt and Greifensee; measurement campaign 2004/2005). http://www.awel.zh.ch/internet/baudirektion/awel/ de/wasserwirtschaft/veroeffentlichungen.html. Accessed 15 November 2012

Balkema AJ, Preisig HA, Otterpohl R, Lambert AJD, Weijers SR (2001) Developing a model based decision support tool for the identification of sustainable treatment options for domestic wastewater. Water Sci Technol 43(7):265-269

Belton V, Stewart TJ (2003) Multiple criteria decision analysis: an integrated approach. Kluwer Academic Publishers, Dordrecht

Bond SD, Carlson KA, Keeney RL (2008) Generating objectives: can decision makers articulate what they want? Manage Sci 54(1):56-70

Bond SD, Carlson KA, Keeney RL (2010) Improving the generation of decision objectives. Decis Anal 7(3):238-255

Bundi U, Peter A, Frutiger A, Hütte M, Liechti P, Sieber U (2000) Scientific base and modular concept for comprehensive assessment of streams in Switzerland. Hydrobiologia 422(423):477-487

Butler D, McEntee B, Onof C, Hagger A (2007) Sewer storage tank performance under climate change. Water Sci Technol 56(12):29-35

Cashman A, Ashley R (2008) Costing the long-term demand for water sector infrastructure. Foresight 10(3):9-26

Clemen RT, Reilly T (2001) Making hard decisions with decision tools ${ }^{\circledR}$, 2nd edn. Duxbury, Brooks/Cole

Daily GC, Soderqvist T, Aniyar S, Arrow K, Dasgupta P et al (2000) The value of nature and the nature of value. Science 289:395-396

Dominguez D, Truffer B, Gujer W (2011) Tackling uncertainty in infrastructure sectors through strategic planning: the contribution of discursive approaches in the urban water sector. Water Policy 13(3):299-316

Dong C, Shoups G, van de Giesen N (2013) Scenario development for water resource planning and management: a review. Technol Forec Soc Change 80(4):749-761

Eder G, Duckstein L, Nachtnebel HP (1997) Ranking water resource projects and evaluating criteria by multicriterion Q-analysis: an Austrian case study. J Multi Crit Decis Anal 6(5):259-271

Egger C, Scheidegger A, Reichert P, Maurer M (2013) Sewer deterioration modelling with data lacking historical records. Water Res 47:6762-6779

Eisenführ F, Weber M, Langer T (2010) Rational decision making, 1st edn. Springer Verlag, Berlin

FOEN (2010) Swiss Federal Office for the Environment. Methoden zur Untersuchung und Beurteilung der Fliessgewässer; chemisch-physikalische Erhebungen, Nährstoffe; in German (Methods for the investigation and assessment of watercourses; chemico-physical parameters, nutrients). http://www. umwelt-schweiz.ch/uv-1005-d. Accessed 15 November 2012

Goodwin P, Wright G (2001) Enhancing strategy evaluation in scenario planning: a role for decision analysis. J Manage Stud 38(1):1-16

Gregory R, Failing L, Harstone M, Long G, McDaniels T, Ohlson D (2012a) Structured decision making: a practical guide to environmental management choices. Wiley-Blackwell, New York

Gregory R, Long G, Colligan M, Geiger JG (2012b) When experts disagree (and better science won't help much): using structured deliberations to support endangered species recovery planning. J Environ Manage 105:30-43

Guest JS, Skerlos SJ, Barnard JL, Beck MB, Daigger GT, Hilger H, Jackson SJ, Karvazy K, Kelly L, Macpherson L, Mihelcic JR, Pramanik A, Raskin L, van Loosdrecht MCM, Yeh D, Love NG (2009) A new planning and design paradigm to achieve sustainable resource recovery from wastewater. Environ Sci Technol 43(16):6126-6130 
Hajkowicz S, Collins K (2007) A review of multiple criteria analysis for water resource planning and management. Water Resour Manage 21:1553-1566

Hämäläinen R, Kettunen E, Marttunen M, Ehtamo H (2001) Evaluating a framework for multistakeholder decision support in water resources management. Group Decis Negot 10(4):331-353

Howard RA (1988) Decision-analysis_practice and promise. Manage Sci 34(6):679-695

Huang IB, Keisler J, Linkov I (2011) Multi-criteria decision analysis in environmental sciences: 10 years of applications and trends. Sci Total Environ 409(19):3578-3594

iWaQa (2013) Integrated river water quality management. Project of the National Research Program NRP 61. http://www.nfp61.ch/E/projects/cluster-water-management/integrated-river_water-quality_ management/Pages/default.aspx. Accessed 06 December 2013

Janis I (1972) Victims of Groupthink. Houghton Mifflin, Boston

Janis I (1982) Groupthink: psychological studies of policy decisions and fiascoes, 2nd edn. Houghton Mifflin, Boston

Karvetski CW, Lambert JH, Linkov I (2009) Emergent conditions and multi-criteria analysis for infrastructure prioritization: methodology and application in developing countries. J Multi Crit Decis Anal 16(5-6):125-137

Karvetski CW, Lambert JH, Linkov I, Keisler J (2011) Integration of decision analysis and scenario planning for coastal engineering and climate change. IEEE Trans Syst Man Cybern Paart A Syst Hum 41(1):63-73

Keeney RL (1992) Value-focused thinking: a path to creative decision making. Harvard University Press, Cambridge

Keeney RL, Raiffa H (1976) Decisions with multiple objectives: preferences and value tradeoffs. John Wiley and Sons, New York

Keeney RL, McDaniels TL, RidgeCooney VL (1996) Using values in planning wastewater facilities for metropolitan Seattle. Water Res Bulletin 32(2):293-303

Kerr NL, Tindale RS (2004) Group performance and decision making. Annu Rev Psychol 55:623-655

Kodikara PN, Perera BJC, Kularathna MDUP (2010) Stakeholder preference elicitation and modelling in multi-criteria decision analysis - a case study on urban water supply. Eur J Oper Res 206:209-220

Kysely J, Gaal L, Beranova R, Plavcova E (2011) Climate change scenarios of precipitation extremes in Central Europe from ENSEMBLES regional climate models. Theor Appl Climatol 104(3-4):529-542

Lambert J, Karvetski C, Spencer D, Sotirin B, Liberi D, Zaghloul H, Koogler J, Hunter S, Goran W, Ditmer R, Linkov I (2012) Prioritizing infrastructure investments in Afghanistan with multiagency stakeholders and deep uncertainty of emergent conditions. J Infrastruct Syst 18(2):155-166

Lang DJ, Wiek A, Bergmann M, Stauffacher M, Martens P, Moll P, Swilling M, Thomas CJ (2012) Transdisciplinary research in sustainability science: practice, principles, and challenges. Sustain Sci 7(1):25-43

Langhans SD, Reichert P (2011) Einbettung von Verfahren zur Fliessgewässerbewertung in ein übergeordnetes Gewässermanagementkonzept; Vorschläge am Beispiel des Modulstufenkonzepts; in German (Embedding procedures for stream assessment into an overriding water management concept; propositions using the example of the Swiss Modular Concept). Wasser Energie Luft 103(3):204-214

Langhans SD, Lienert J, Schuwirth N, Reichert P (2013) How to make river assessments comparable: a demonstration for hydromorphology. Ecol Indic 32:264-275

Larsen TA, Alder AC, Eggen RIL, Maurer M, Lienert J (2009) Source separation: will we see a paradigm shift in wastewater handling? Environ Sci Technol 43(16):6121-6125

Larsen TA, Udert KM, Lienert J (2012) Source separation and decentralization for wastewater management. IWA Publishing, London ISBN 9781843393481 (Paperback), ISBN 9781780401072 (eBook)

Libralato G, Volpi Ghirardini A, Avezzù F (2012) To centralise or to decentralise: an overview of the most recent trends in wastewater treatment management. J Environ Manage 94(1):61-68

Lienert J, Monstadt J, Truffer B (2006) Future scenarios for a sustainable water sector: a case study from Switzerland. Environ Sci Technol 40(2):436-442

Lienert J, Schnetzer F, Ingold K (2013) Stakeholder analysis combined with social network analysis provides fine-grained insights into water infrastructure planning processes. J Environ Manage 125:134-148

Lienert J, Scholten L, Egger C, Maurer M (2014) Additional information for Structured decision-making for sustainable water infrastructure planning and four future scenarios. In: Working Papers in 
Environmental Social Sciences 2014-03, Department of Environmental Social Sciences, Swiss Federal Institute of Aquatic Science and Technology (Eawag), Dübendorf, Switzerland. http://www. eawag.ch/forschung/ess/workingpapers/. Accessed 27 June 2014

Likert R (1932) A technique for the measurement of attitudes. Archiv Psychol 140:1-55

Linkov I, Moberg E (2012) Multi-criteria decision analysis. Environmental applications and case studies. CRC Press, Boca Raton

Lundie S, Peters GM, Beavis PC (2004) Life cycle assessment for sustainable metropolitan water systems planning. Environ Sci Technol 38(13):3465-3473

Martin P (2009) Wiederbeschaffungswert der Umweltinfrastruktur. Umfassender Überblick für die Schweiz; in German (Replacement value of the environmental infrastructure. Overview for Switzerland). Umwelt-Wissen Nr. 0920. Bundesamt für Umwelt, BAFU (Swiss Federal Office for the Environment, FOEN). http://www.bafu.admin.ch/publikationen/index.html?lang=en. Accessed 06 December 2013

Maurer M, Rothenberger D, Larsen TA (2005) Decentralised wastewater treatment technologies from a national perspective: at what cost are they competitive? Water Sci Technol 5(6):145-154

Milly PCD, Betancourt J, Falkenmark M, Hirsch RM, Kundzewicz ZW, Lettenmaier DP, Stouffer RJ (2008) Climate change-stationarity is dead: whether water management? Science 319(5863):573-574

Montibeller G, Gummer H, Tumidei D (2006) Combining scenario planning and multi-criteria decision analysis in practice. J Multi Crit Decis Anal 14(1-3):5-20

Nutt P (2004) Expanding the search for alternatives during strategic decision making. Acad Manage Exec 18(4):13-28

OECD (2012) http://stats.oecd.org/Index.aspx?DatasetCode=SNA_TABLE1. Data extracted on 28 August 2012, 12:51 UTC(GMT)

Osborn AF (1963) Applied imagination: principles and procedures of creative problem solving, 3rd edn. C Scribner, NY

Palme U, Lundin M, Tillman A-M, Molander S (2005) Sustainable development indicators for wastewater systems-researchers and indicator users in a co-operative case study. Resour Conserv Recycl 43:293-311

Patz JA, Vavrus SJ, Uejio CK, McLellan SL (2008) Climate change and waterborne disease risk in the Great Lakes region of the US. Am J Prev Med 35:451-458

Peterson GD, Cumming GS, Carpenter SR (2003) Scenario planning: a tool for conservation in an uncertain world. Cons Biol 17(2):358-366

Ram C, Montibeller G (2013) Exploring the impact of evaluating strategic options in a scenario-based multi-criteria framework. Technol Forecast Soc Chang 80(4):657-672

Ram C, Montibeller G, Morton A (2011) Extending the use of scenario planning and MCDA for the evaluation of strategic options. J Oper Res Soc 62(5):817-829

Reichert P, Borsuk M, Hostmann M, Schweizer S, Sporri C, Tockner K, Truffer B (2007) Concepts of decision support for river rehabilitation. Environ Modell Softw 22(2):188-201

Reichert P, Langhans S, Lienert J, Schuwirth N (2014) The conceptual foundation of environmental decision support. Submitted

Renner R, Schneider F, Hohenwallner D, Kopeinig C, Kruse S, Lienert J, Link S, Muhar S (2013) Meeting the challenges of transdisciplinary knowledge production for sustainable water governance. Mt Res Dev 33(3):234-247

Ringland G (2002) Scenario planning managing for the future. John Wiley \& Sons, Chichester

Scheidegger A, Hug T, Rieckermann J, Maurer M (2011) Network condition simulator for benchmarking sewer deterioration models. Water Res 45:4983-4994

Scheidegger A, Scholten L, Maurer M, Reichert P (2013) Extension of pipe failure models to consider the absence of data from replaced pipes. Water Res 47:3696-3705

Schnaars SP (1987) How to develop and use scenarios. Long Range Plann 20(1):105-114

Schoemaker PJH (1995) Scenario planning: a tool for strategic thinking. Sloan Manage Rev 36(2):25-40

Scholten L, Scheidegger A, Reichert P, Maurer M (2013) Combining expert knowledge and local data for improved service life modeling of water supply networks. Environ Modell Softw 42:1-16

Scholten L, Scheidegger A, Reichert P, Maurer M, Lienert J (2014a) Strategic rehabilitation planning of piped water networks using multi-criteria decision analysis. Water Res 49:124-143

Scholten L, Schuwirth N, Reichert P, Lienert J (2014b) Tackling uncertainty in multi-criteria decision analysis - an application to water supply infrastructure planning (submitted) 
Schulz M, Renn O (eds) (2009) Das Gruppendelphi; Konzept und Fragebogenkonstruktion; in German (The group delphi; concept and questionnaire construction) VS Verlag für Sozialwissenschaften. GWV Fachverlage GmbH, Wiesbaden

Schuwirth N, Stamm C, Reichert P (2012) Incorporation of uncertainty in decision support to improve water quality. In: Seppelt R, Voinov AA, Lange S, Bankamp D (eds) International congress on environmental modelling and software. Sixth Biennial Meeting, Leipzig, Germany, pp 1005-1012. http://www.iemss.org/sites/iemss2012//proceedings/D1_2_0578_\%20Schuwirth_et_al.pdf

Stewart TJ (2005) Dealing with uncertainties in MCDA. In: Figueira J, Greco S, Ehrgott M (eds) Multiple criteria decision analysis, state of the Art Surveys. Springer, Berlin, pp 445-470

Stewart TJ, French S, Rios J (2013) Integrating multicriteria decision analysis and scenario planning-a review and extension. Omega Int J Manage Sci 41(4):679-688

Störmer E, Truffer B, Dominguez D, Gujer W, Herlyn A, Hiessl H, Kastenholz H, Klinke A, Markard J, Maurer M, Ruef A (2009) The exploratory analysis of trade-offs in strategic planning: lessons from regional infrastructure foresight. Technol Forecast Soc Chang 76(9):1150-1162

Swart RJ, Raskin P, Robinson J (2004) The problem of the future: Sustainability science and scenario analysis. Global Environ Change Human Policy Dimens 14(2):137-146

SWIP (2014) Sustainable Water Infrastructure Planning. Project of the National Research Program NRP 61. http://www.eawag.ch/forschung/sww/gruppen/swip/index_EN Accessed 16 April 2014

Tilanus CB, de Gans OB, Lenstra JK (1983) Postscript: a survey of reasons for failure or success of quantitative methods in management. In: de Gans OB, Lenstra JK, Tilanus CB (eds) Quantitative methods in management: case studies of failures and successes. Wiley, New York, pp 269-273

Truffer B, Störmer E, Maurer M, Ruef A (2010) Local strategic planning processes and sustainability transitions in infrastructure sectors. Environ Policy Gov 20(4):258-269

VSA (2002) Verband Schweizerischer Abwasser- und Gewässerschutzfachleute (Association of Swiss wastewater and water protection experts). Regenwasserentsorgung. Richtlinie zur Versickerung, Retention und Ableitung von Niederschlagswasser in Siedlungsgebieten; in German (Rain water disposal. Guideline for infiltration, retention and discharge of stormwater in urban areas). http:// www.vsa.ch/en/publikationen/shop/. Accessed 09 January 2013

Wack P (1985) Scenarios: uncharted waters ahead. Harvard Bus Rev 63(5):72-89

Walker WE, Marchau VAWJ, Swanson D (2010) Addressing deep uncertainty using adaptive policies: introduction to section 2. Technol Forecast Soc Chang 77(6):917-923

WCED (1987) World commission on environment and development. Our common future. Oxford University Press, Oxford

Wuelser G, Pohl C, Hirsch Hadorn G (2012) Structuring complexity for tailoring research contributions to sustainable development: a framework. Sustain Sci 7(1):81-93

Zheng J, Egger C, Lienert J. (2014) Multi-criteria decision analysis for wastewater infrastructure planning incorporating stakeholders preferences (working title, in preparation) 